\title{
Avaliação de concretos reciclados com agregado graúdo de concreto dosados pelo método da ABCP modificado
}

\author{
Evaluation of recycled concrete with concrete coarse \\ aggregate using ABCP mix design method modified
}

\section{Ana Amélia Mota dos Santos Mônica Batista Leite}

\section{Resumo \\ A}

aplicação de agregados reciclados de resíduos de construção e demolição vem crescendo em todo o mundo. Contudo, a adoção de um método de dosagem que não considere aspectos como o tipo de agregado reciclado (AR), o melhor teor de $\mathrm{AR}$ na proporção das misturas e a melhor forma de avaliar a trabalhabilidade pode trazer dificuldades para essa aplicação. Assim, este trabalho foi desenvolvido com o objetivo de realizar uma dosagem específica para os concretos com AR de concreto, usando como medida de trabalhabilidade o ensaio de espalhamento na mesa de Graff, como uma adaptação do método de dosagem da ABCP. Foram avaliados dois níveis de espalhamento (350 $\mathrm{mm}$ e $400 \mathrm{~mm}$ ) e estudados dois teores de AR na proporção de agregados graúdos (20\% e $40 \%)$ para três níveis de resistência de dosagem $(25,30$ e $40 \mathrm{MPa})$ aos 28 dias. Os resultados mostraram que foi necessário realizar muitos ajustes experimentais nas misturas de concreto inicialmente determinadas pelo método de dosagem da $\mathrm{ABCP}$, e o ensaio de espalhamento na mesa de Graff mostrou-se satisfatório como medida de trabalhabilidade desses concretos. Os níveis de espalhamento avaliados apresentaram influência significativa sobre os resultados de resistência à compressão, enquanto os teores de AR avaliados neste estudo (20\% e 40\%) não promoveram alterações dessa propriedade.

Palavras-chave: Dosagem. Concreto reciclado. Agregado reciclado de concreto. Resíduo de construção e demolição.

\begin{abstract}
The use of recycled aggregate from construction and demolition waste is growing throughout the world. However, the adoption of a mix design method that does not take into account the type of recycled aggregate (RA), the best $R A$ content in the mix proportion, and the best way to evaluate workability can hinder its application. Hence, the main goal of this study is to develop a specific mix design of recycled concrete, using the flow test on Graff's Table as a measure of workability. The mix design adopted was an adaptation of the ABCP (Brazilian Portland Cement Association) method. The RA proportions were $20 \%$ and $40 \%$. In addition, the influence of two levels of flow test $(350 \mathrm{~mm}$ and $400 \mathrm{~mm}$ ) and three different mix design strength levels $(25,30$ and $40 \mathrm{MPa})$ were also tested.The results showed it was necessary to make many experimental adjustments in the concrete mixtures determined by the ABCP method. On the other hand, the flow test on the Graff's table proved to be satisfactory as a measure of recycled concrete workability in this study. The two flow test levels evaluated had a significant influence on the compressive strength results, while the RA contents evaluated $(20 \%$ and $40 \%)$ did not affect this property.
\end{abstract}

Recebido em 10/07/16

Aceito em 09/03/18

${ }^{1}$ Ana Amélia Mota dos Santos Universidade Estadual de Feira de

${ }^{2}$ Mônica Batista Leite 2Universidade Estadual de Feira de

Santana
Feira de Santana - BA - Brasil
Keywords: Mix design. Recycled concrete. Recycled concrete aggregate. Construction and demolition waste. 


\section{Introdução}

A construção civil é responsável por elevado consumo de recursos naturais, entre os quais estão os agregados minerais, utilizados comumente na produção de argamassas e concretos. A exploração das jazidas desses agregados resulta na escassez de matéria-prima natural e ainda na degradação do meio ambiente. Em paralelo, existe outro impacto ambiental causado pela construção civil, a geração de resíduos de construção e demolição (RCD). A problemática da geração do RCD é comum a diversos países do mundo e tem se tornado crescente à proporção que a indústria da construção se desenvolve. A reciclagem se apresenta como uma solução sustentável para a destinação do RCD, pois, além de promover a economia no uso de matéria-prima natural, resulta na diminuição da poluição ambiental causada. De acordo com Ferreira (2007), a utilização do RCD como agregados, por exemplo, apresenta vantagens econômicas, principalmente em países onde as jazidas desses materiais estão cada vez mais escassas. Porém, o uso do RCD como agregado requer estudo prévio da influência desse material nas propriedades dos concretos $\mathrm{e}$ argamassas, nos estados fresco e endurecido (ÂNGULO, 2005).

Nos últimos anos, vários pesquisadores, em diversos países, têm desenvolvido estudos para contribuir com o aumento do conhecimento sobre o comportamento de concretos com agregados de RCD (RAVINDRARAJAH, 1987; BAIRAGI; VIDYADHARA; RAVANDE, 1990; TOPÇU; GÜNÇAN, 1995; LEITE, 2001; POON et al., 2004; TAM; GAO; TAM, 2005; BRITO, 2005, RAHMAN; HAMDAM; ZAIDI, 2009; PACHECO-TORGAL; JALALI, 2010; LOVATO et al., 2012, MATIAS et al., 2013; LEITE; MONTEIRO, 2016; SILVA; ANDRADE, 2017, entre outros). Os resultados apontaram que as características dos agregados reciclados (AR), como elevada porosidade e absorção de água, forma irregular e textura rugosa e baixa resistência do grão, influenciaram significativamente na qualidade dos concretos produzidos, que, de modo geral, apresentaram dificuldades para atingir as propriedades requeridas.

Diversos autores observaram problemas na trabalhabilidade dos concretos reciclados quando esta foi avaliada pelo ensaio do abatimento do tronco de cone. Dessa forma, durante a dosagem foi necessário aumentar a quantidade de água das misturas, elevando-se a relação água-cimento $(\mathrm{a} / \mathrm{c})$ efetiva desses concretos (MOREIRA, 2010; FONSECA; BRITO; EVANGELISTA, 2011; GONZÁLEZ-FONTEBOA et al., 2012; LOVATO et al., 2012; PADOVAN, 2013; SEARA-PAZ et al.,2014). Esses resultados foram atribuídos à alta taxa absorção de água dos ARs, que provoca a redução da quantidade de água de amassamento, resultando em misturas mais consistentes. O aumento da relação a/c efetiva dos concretos, através da compensação da absorção de água do $\mathrm{AR}$, não fez com que os resultados de abatimento dos concretos reciclados fossem iguais ao do concreto de referência (VIEIRA, 2003; RODRIGUES; FUCALE, 2014). A textura rugosa e a forma irregular apresentada pelos ARs provocam um efeito de travamento entre grãos e redução da mobilidade das misturas, o que resulta em redução do abatimento, mesmo com o aumento no teor de água (FIGUEIRÊDO FILHO, 2011). Dessa forma, Leite (2001) e Malta (2012) afirmam que o ensaio de abatimento do tronco de cone não é o mais adequado para medir a trabalhabilidade de concretos com ARs.

Com base em tais observações, Moitinho e Leite (2015) produziram misturas de concreto reciclado utilizando como medida de trabalhabilidade o ensaio de espalhamento na mesa de Graff. Os autores concluíram que esse ensaio apresentou-se satisfatório para as dosagens realizadas, uma vez que as misturas produzidas alcançaram o valor de espalhamento previamente estabelecido. Além disso, observou-se que os resultados alcançados também podem ser atribuídos à compensação de $50 \%$ da taxa de absorção de água do AR, à utilização de superplastificantes e ao método de mistura adotado.

Do mesmo modo, Leite, Figueiredo Filho e Lima (2013) apontam a necessidade do uso de superplastificantes, da compensação parcial da taxa de absorção de água do AR e da utilização de um método específico de mistura para a melhoria da trabalhabilidade do concreto reciclado, como o método proposto por Tam, Gao e Tam (2005). Os autores afirmam também que os testes de tempo VeBe e espalhamento na mesa de Graff são mais adequados para determinar a trabalhabilidade do concreto reciclado, uma vez que utilizam um componente dinâmico durante o ensaio. $\mathrm{O}$ uso de ensaios desse tipo reduz a viscosidade e o atrito interno das misturas de concreto reciclado, mesmo para pequenos incrementos de teor de água. O teste de espalhamento na mesa de Graff foi considerado mais adequado quando comparado ao tempo $\mathrm{VeBe}$, por se tratar de um equipamento simples e facilmente aplicável a canteiros de obras, além de ser de fácil manuseio e apresentar reduzida influência do operador na obtenção dos resultados (LEITE; FIGUEIREDO FILHO; LIMA, 2013). 
Apesar dos resultados satisfatórios de trabalhabilidade, obtidos por Moitinho e Leite (2015), os concretos produzidos com AR de argamassa apresentaram redução da resistência mecânica quando comparados ao concreto de referência. Resultados similares de perda de resistência para concretos reciclados foram observados por outros autores (FONSECA, 2006; SANTOS, 2006; NUNES, 2007). Essas reduções podem ser atribuídas ao tipo de agregado utilizado, que apresenta maior porosidade e menor resistência do grão, e, de acordo com Leite (2001), tendem apresentar um comportamento mecânico inferior ao apresentado pelo agregado natural (AN). Além disso, a menor massa específica apresentada por esses agregados aumenta a porosidade do concreto e, consequentemente, reduz sua resistência (MOREIRA, 2010; GONÇALVES, 2011; LOVATO et al., 2012).

Por esse motivo, afirma-se que concretos com ARs de concreto, que, de modo geral, apresentam melhores características quando comparados a outros tipos de ARs, proporcionam resultados de resistência à compressão semelhantes aos apresentados pelos concretos convencionais. Porém, observa-se que existe um limite para o teor de substituição desses agregados, que, de maneira geral, não deve ultrapassar os 50\%, uma vez que, para substituições acima desse percentual, se obtêm maiores reduções da resistência mecânica do concreto reciclado, quando comparado ao concreto convencional (WERLE, 2010; SAFIUDDIN; ALENGARAM; SALAMB, 2011; CAVALHEIRO, 2011; KWAN et al., 2012; MATIAS et al.,2013; LEITE; MONTEIRO, 2016).

É importante salientar que a maioria dos estudos disponíveis na literatura tem em comum o fato de realizarem substituições, geralmente em volume, dos agregados naturais por diferentes teores de agregados reciclados para produção dos concretos. Raros são os estudos específicos de dosagem de concreto reciclado que consideram o AR como parte dos materiais para realizar o proporcionamento das misturas (FATHIFAZL et al., 2009; RODRIGUES; FUCALE, 2014; MALTA, 2012; AMARIO, 2015). Ainda assim, com os resultados desses estudos, observou-se redução da trabalhabilidade para as misturas com agregado reciclado, medidas pelo abatimento do tronco de cone, e não foi possível observar influência do método de dosagem sobre os resultados dos concretos no estado endurecido.

Com base no exposto, estabelecer a dosagem de concretos reciclados não se resume apenas à determinação do melhor proporcionamento entre as misturas. Devem-se considerar aspectos como tipo de $\mathrm{AR}$, teor de $\mathrm{AR}$ usado na proporção da mistura, uso de aditivos químicos, processo de produção e forma de avaliar a trabalhabilidade, entre outros fatores. Assim, este estudo foi desenvolvido com o objetivo de realizar uma dosagem específica de concretos reciclados com agregados graúdos reciclados de concreto utilizando uma adaptação do método da $\mathrm{ABCP}$, descrito por Rodrigues (1995). A adaptação do método da ABCP consistiu em desenvolver essa dosagem usando a medida do espalhamento na mesa de Graff como parâmetro de avaliação da trabalhabilidade. Neste estudo foi analisada a influência de dois teores de AR de concreto $(20 \%$ e 40\%) na proporção das misturas e dois níveis de espalhamento na mesa de Graff $(350 \mathrm{~mm}$ e 400 $\mathrm{mm}$ ) sobre a trabalhabilidade e a resistência à compressão dos concretos produzidos.

\section{Programa experimental}

\section{Materiais}

Para a produção dos concretos, foi utilizado o cimento Portland composto com pozolana resistente a sulfatos (CP II Z $32 \mathrm{RS}$ ), classe 32 $\mathrm{MPa}$, cuja massa específica é $3,00 \mathrm{~kg} / \mathrm{dm}^{3}$. Foi utilizado o aditivo Adiment, da marca Vedacit, com densidade de $1,12 \mathrm{~g} / \mathrm{cm}^{3}$ (informação fornecida pelo fabricante) e teor de sólidos de $19 \%$.

Foram utilizadosdois tipos de agregados miúdos naturais (AMN): uma areia fina quartzosa (AMN1), proveniente de jazidas da cidade de Alagoinhas, BA, com massa específica de 2,62 $\mathrm{kg} / \mathrm{dm}^{3}$ e massa unitária de $1,60 \mathrm{~kg} / \mathrm{dm}^{3}$, e uma areia média de origem fluvial (AMN2), proveniente do rio Paraguaçu, região de Santos Estevão, BA, com massa específica de $2,61 \mathrm{~kg} / \mathrm{dm}^{3}$ e massa unitária de $1,42 \mathrm{~kg} / \mathrm{dm}^{3}$. Para a produção dos concretos foi utilizada uma mistura de $75 \%$ de AMN1 e $25 \%$ de AMN2, com o objetivo de obter um agregado miúdo com melhor composição granulométrica. A dimensão máxima característica do agregado miúdo composto obtido (75\%AMN1$25 \%$ AMN2) foi de $2,4 \mathrm{~mm}$, e o módulo de finura igual a 2,00.

O agregado graúdo natural (AGN) utilizado foi uma brita de origem granítica proveniente do município de Conceição do Jacuípe, BA. O agregado graúdo reciclado (AGR) utilizado foi obtido a partir do beneficiamento de corpos de prova de concreto adquiridos de uma fábrica de pré-moldados localizada na cidade de Feira de Santana, BA. O processo de beneficiamento consistiu na britagem, em britador de mandíbulas, e peneiramento do resíduo para separação da fração graúda (material passante na peneira de 19 
$\mathrm{mm}$ e retido na peneira de $4,8 \mathrm{~mm}$ ). As características dos agregados graúdos utilizados estão apresentadas na Tabela 1 , e as curvas granulométricas desses agregados, na Figura 1.

Conforme observado na Tabela 1, o AGR não apresentou em sua composição material pulverulento. Atribui-se esse resultado à eliminação dos finos durante $\mathrm{o}$ processo de beneficiamento do agregado reciclado, uma vez que a fração utilizada nesta pesquisa foi composta pelo material passante na peneira de $19 \mathrm{~mm}$ e retido na peneira de $4,8 \mathrm{~mm}$. Dessa forma, os finos, que normalmente compõem a fração miúda, foram removidos da fração utilizada. $O$ teor de argamassa antiga aderida ao AGR de concreto foi de $62 \%$, medido conforme metodologia descrita por Jordani (2016), e o teor de pasta correspondente foi de $17,7 \%$. O índice de perda por abrasão Los Angeles apresentado pelo agregado reciclado foi de $27,1 \%$, inferior ao apresentado pelo agregado natural, de 39,4\%. Esse resultado difere do esperado, uma vez que agregados reciclados normalmente apresentam menor resistência ao desgaste por abrasão quando comparados ao agregado natural. Porém, é possível supor que o desempenho do material reciclado pode ter sido influenciado pela melhor qualidade do agregado natural presente no concreto que deu origem ao agregado reciclado, se comparado ao agregado natural utilizado nesta pesquisa. Conforme apontado por Zega e Maio (2009), concretos produzidos com agregados naturais de melhor qualidade podem gerar agregados reciclados mais resistentes ao desgaste por abrasão que alguns agregados naturais. Além disso, pode- se atribuir esse comportamento ao elevado teor de pasta presente no AGR de concreto utilizado, o que também pode promover um menor índice de perda por abrasão.

\section{Dosagem e produção}

O estudo de dosagem dos concretos reciclados foi realizado de acordo com o método de dosagem da ABCP (RODRIGUES, 1995). A adaptação do método consistiu em utilizar como medida de trabalhabilidade o ensaio de espalhamento na mesa de Graff. Neste estudo trabalhou-se com dois níveis de espalhamento: o nível 1, para obtenção de concretos de consistência plástica $(\mathrm{N} 1=350 \pm 20 \mathrm{~mm}$ ); e o nível 2, para concretos de consistência fluida $(\mathrm{N} 2=400 \pm 20 \mathrm{~mm})$, conforme critérios estabelecidos por Leite, Figueiredo Filho e Lima (2013). Além disso, avaliaram-se dois teores de agregado graúdo reciclado de concreto (20\% e $40 \%$ ) na proporção de agregados graúdos. As misturas foram identificadas de acordo com o teor de AR $(20 \%$ e $40 \%)$ e com o nível de espalhamento requerido (N1 e N2).

A primeira etapa de aplicação do método deu-se pelo estudo teórico, com a definição dos parâmetros iniciais de entrada (Tabela 2), o cálculo dos consumos de materiais e a definição do traço unitário, em massa, para cada mistura (Tabela 3). Os parâmetros iniciais de entrada foram obtidos a partir de informações da caracterização dos materiais utilizados na produção dos concretos e da utilização de quadros, ábacos, tabelas e equações fornecidos pelo método da $\mathrm{ABCP}$ (RODRIGUES, 1995).

\section{Tabela 1 - Resultados da caracterização dos agregados graúdos}

\begin{tabular}{|c|c|c|c|c|}
\hline \multicolumn{2}{|c|}{ Propriedades Avaliadas - Métodos de Ensaio } & AGN & AGR & $\begin{array}{c}\text { Limites da NBR } \\
7211(2009)\end{array}$ \\
\hline \multicolumn{2}{|c|}{ Dimensão máxima característica $(\mathrm{mm})$ - NM 248 (ABNT, 2003a) } & 19 & 19 & - \\
\hline \multicolumn{2}{|c|}{ Módulo de finura - NBR NM 248 (ABNT, 2003a) } & 6,68 & 6,71 & - \\
\hline \multirow{3}{*}{$\begin{array}{c}\text { Massa específica }\left(\mathrm{kg} / \mathrm{dm}^{3}\right)-\mathrm{NBR} \text { NM } 53 \\
(\mathrm{ABNT}, 2003 \mathrm{~b})\end{array}$} & Aparente & 2,79 & 2,76 & - \\
\hline & $\begin{array}{c}\text { Saturada } \\
\text { Superfície seca }\end{array}$ & 2,77 & 2,56 & - \\
\hline & Seco & 2,76 & 2,45 & - \\
\hline \multicolumn{2}{|c|}{ Massa específica $\left(\mathrm{kg} / \mathrm{dm}^{3}\right)$ - Leite $(2001)$} & - & 2,72 & - \\
\hline \multicolumn{2}{|c|}{ Massa unitária $\left(\mathrm{kg} / \mathrm{dm}^{3}\right)$ - NBR NM 45 (ABNT, 2006a) } & 1,50 & 1,30 & - \\
\hline \multicolumn{2}{|c|}{ Absorção de água (\%) - NBR NM 53 (ABNT, 2003b) } & 0,4 & 4,5 & - \\
\hline \multicolumn{2}{|c|}{ Absorção de água (\%) - Leite (2001) } & - & 5,0 & - \\
\hline \multicolumn{2}{|c|}{ Abrasão Los Angeles (\%) - NBR NM 51 (ABNT, 2001) } & 39,4 & 27,1 & $\leq 50$ \\
\hline \multicolumn{2}{|c|}{ Índice de forma - NBR 7809 (ABNT, 2006b) } & 2,6 & 2,5 & $\leq 3$ \\
\hline \multicolumn{2}{|c|}{ Material pulverulento (\%) - NBR NM 46 (ABNT, 2003c) } & 0,2 & 0,0 & $<1$ \\
\hline \multicolumn{2}{|c|}{ Teor de argamassa antiga aderida $(\%)$ - Jordani (2016) } & - & 62,0 & - \\
\hline
\end{tabular}


Figura 1 - Curvas granulométricas dos agregados graúdos, natural e reciclado, e respectivos limites inferior e superior da zona granulométrica $(9,5 / 25,0)$ especificada pela NBR 7211 (ABNT, 2009)

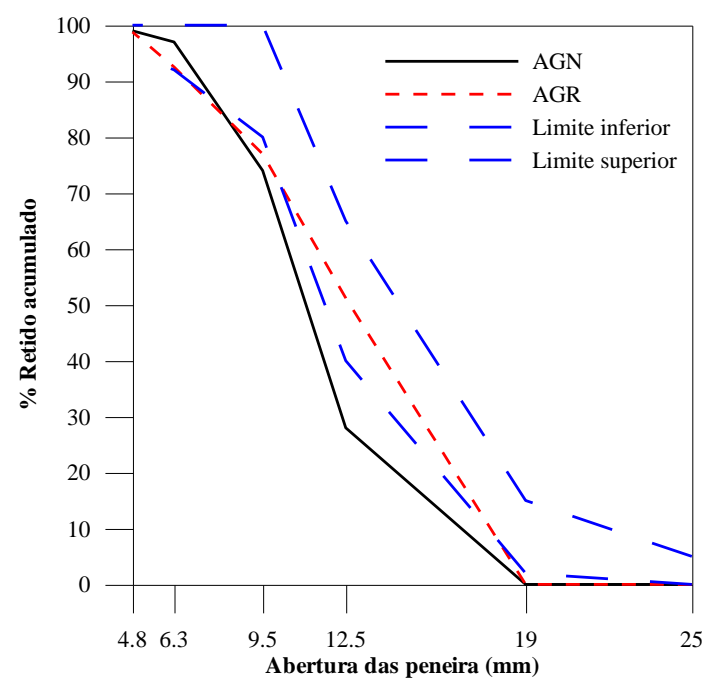

Tabela 2 - Parâmetros iniciais de entrada para a obtenção dos traços de concreto reciclado a serem produzidos pelo método da $A B C P$

\begin{tabular}{|c|c|c|c|c|}
\hline \multicolumn{5}{|c|}{ Família de concreto 1 - N1 - $20 \%$ AGR } \\
\hline$f_{c d}$ & $\begin{array}{c}\text { Relação a/c } \\
\text { Consumo de água (kg) }\end{array}$ & $\begin{array}{l}\text { Consumo de } \\
\text { cimento }(\mathrm{kg})\end{array}$ & $\begin{array}{l}\text { Volume de brita } \\
\left(\mathrm{m}^{3}\right)\end{array}$ & $\begin{array}{l}\text { Volume de miúdo } \\
\left(\mathrm{m}^{3}\right)\end{array}$ \\
\hline $25 \mathrm{MPa}$ & $\begin{array}{l}\mathrm{a} / \mathrm{c}=0,60 \\
\mathrm{C}_{\text {água }}=200\end{array}$ & $\mathrm{C}_{\mathrm{cim}}=333$ & $\begin{array}{l}V_{c-p 1}=0,60 \\
V_{c-p 2}=0,15\end{array}$ & $\begin{array}{l}\mathrm{V}_{\mathrm{m}-\mathrm{a} 1}=0,22 \\
\mathrm{~V}_{\mathrm{m}-\mathrm{a} 2}=0,07\end{array}$ \\
\hline $30 \mathrm{MPa}$ & $\begin{array}{c}\mathrm{a} / \mathrm{c}=0,52 \\
\mathrm{C}_{\text {água }}=200\end{array}$ & $\mathrm{C}_{\mathrm{cim}}=385$ & $\begin{array}{l}V_{c-p 1}=0,60 \\
V_{c-p 2}=0,15\end{array}$ & $\begin{array}{l}V_{\mathrm{m}-\mathrm{a} 1}=0,21 \\
\mathrm{~V}_{\mathrm{m}-\mathrm{a} 2}=0,07\end{array}$ \\
\hline $40 \mathrm{MPa}$ & $\begin{array}{c}\mathrm{a} / \mathrm{c}=0,42 \\
\mathrm{C}_{\text {água }}=200\end{array}$ & $\mathrm{C}_{\mathrm{cim}}=476$ & $\begin{array}{l}V_{c-p 1}=0,60 \\
V_{c-p 2}=0,15\end{array}$ & $\begin{array}{l}\mathrm{V}_{\mathrm{m}-\mathrm{a} 1}=0,19 \\
\mathrm{~V}_{\mathrm{m}-\mathrm{a} 2}=0,06\end{array}$ \\
\hline \multicolumn{5}{|c|}{ Família de concreto 2 - N2 - 20\%AGR } \\
\hline$f_{c d}$ & $\begin{array}{c}\text { Relação a/c } \\
\text { Consumo de água (kg) }\end{array}$ & $\begin{array}{l}\text { Consumo de } \\
\text { cimento (kg) }\end{array}$ & $\begin{array}{l}\text { Volume de brita } \\
\left(\mathrm{m}^{3}\right)\end{array}$ & $\begin{array}{l}\text { Volume de miúdo } \\
\left(\mathrm{m}^{3}\right)\end{array}$ \\
\hline $25 \mathrm{MPa}$ & $\begin{array}{c}\mathrm{a} / \mathrm{c}=0,60 \\
\mathrm{C}_{\text {água }}=205\end{array}$ & $\mathrm{C}_{\mathrm{cim}}=342$ & $\begin{array}{l}V_{c-p 1}=0,60 \\
V_{c-p 2}=0,15\end{array}$ & $\begin{array}{l}V_{\mathrm{m}-\mathrm{a} 1}=0,22 \\
\mathrm{~V}_{\mathrm{m}-\mathrm{a} 2}=0,07\end{array}$ \\
\hline $30 \mathrm{MPa}$ & $\begin{array}{c}\mathrm{a} / \mathrm{c}=0,52 \\
\mathrm{C}_{\text {água }}=205\end{array}$ & $\mathrm{C}_{\mathrm{cim}}=394$ & $\begin{array}{l}V_{c-p 1}=0,60 \\
V_{c-p 2}=0,15\end{array}$ & $\begin{array}{l}V_{\mathrm{m}-\mathrm{a} 1}=0,20 \\
\mathrm{~V}_{\mathrm{m}-\mathrm{a} 2}=0,07\end{array}$ \\
\hline $40 \mathrm{MPa}$ & $\begin{array}{c}\mathrm{a} / \mathrm{c}=0,42 \\
\mathrm{C}_{\text {água }}=205\end{array}$ & $\mathrm{Ccim}=488$ & $\begin{array}{l}V_{c-p 1}=0,60 \\
V_{c-p 2}=0,15\end{array}$ & $\begin{array}{l}\mathrm{V}_{\mathrm{m}-\mathrm{a} 1}=0,18 \\
\mathrm{~V}_{\mathrm{m}-\mathrm{a} 2}=0,06\end{array}$ \\
\hline \multicolumn{5}{|c|}{ Família de concreto 3 - N1-40\%AGR } \\
\hline$f_{c d}$ & $\begin{array}{c}\text { Relação a/c } \\
\text { Consumo de água }(\mathrm{kg})\end{array}$ & $\begin{array}{l}\text { Consumo de } \\
\text { cimento }(\mathrm{kg})\end{array}$ & $\begin{array}{l}\text { Volume de brita } \\
\left(\mathrm{m}^{3}\right)\end{array}$ & $\begin{array}{l}\text { Volume de miúdo } \\
\qquad\left(\mathrm{m}^{3}\right)\end{array}$ \\
\hline $25 \mathrm{MPa}$ & $\begin{array}{c}\mathrm{a} / \mathrm{c}=0,60 \\
\mathrm{C}_{\text {água }}=200\end{array}$ & $\mathrm{C}_{\mathrm{cim}}=333$ & $\begin{array}{l}V_{c-p 1}=0,45 \\
V_{c-p 2}=0,30\end{array}$ & $\begin{array}{l}\mathrm{V}_{\mathrm{m}-\mathrm{a} 1}=0,23 \\
\mathrm{~V}_{\mathrm{m}-\mathrm{a} 2}=0,08\end{array}$ \\
\hline $30 \mathrm{MPa}$ & $\begin{array}{c}\mathrm{a} / \mathrm{c}=0,52 \\
\mathrm{C}_{\text {água }}=200\end{array}$ & $\mathrm{C}_{\mathrm{cim}}=385$ & $\begin{array}{l}V_{c-p 1}=0,45 \\
V_{c-p 2}=0,30\end{array}$ & $\begin{array}{l}\mathrm{V}_{\mathrm{m}-\mathrm{a} 1}=0,22 \\
\mathrm{~V}_{\mathrm{m}-\mathrm{a} 2}=0,07\end{array}$ \\
\hline $40 \mathrm{MPa}$ & $\begin{array}{c}\mathrm{a} / \mathrm{c}=0,42 \\
\mathrm{C}_{\text {água }}=200\end{array}$ & $\mathrm{C}_{\mathrm{cim}}=477$ & $\begin{array}{l}V_{c-p 1}=0,45 \\
V_{c-p 2}=0,30\end{array}$ & $\begin{array}{l}\mathrm{V}_{\mathrm{m}-\mathrm{a} 1}=0,19 \\
\mathrm{~V}_{\mathrm{m}-\mathrm{a} 2}=0,06\end{array}$ \\
\hline \multicolumn{5}{|c|}{ Família de concreto $4-\mathrm{N} 2-40 \%$ AGR } \\
\hline $\mathrm{f}_{\mathrm{cd}}$ & $\begin{array}{c}\text { Relação a/c } \\
\text { Consumo de água (kg) }\end{array}$ & $\begin{array}{l}\text { Consumo de } \\
\text { cimento }(\mathrm{kg})\end{array}$ & $\begin{array}{l}\text { Volume de brita } \\
\left(\mathrm{m}^{3}\right)\end{array}$ & $\begin{array}{l}\text { Volume de miúdo } \\
\left(\mathrm{m}^{3}\right)\end{array}$ \\
\hline $25 \mathrm{MPa}$ & $\begin{array}{c}\mathrm{a} / \mathrm{c}=0,60 \\
\mathrm{C}_{\text {água }}=205\end{array}$ & $\mathrm{C}_{\mathrm{cim}}=342$ & $\begin{array}{l}V_{c-p 1}=0,45 \\
V_{c-p 2}=0,30\end{array}$ & $\begin{array}{l}\mathrm{V}_{\mathrm{m}-\mathrm{a} 1}=0,22 \\
\mathrm{~V}_{\mathrm{m}-\mathrm{a} 2}=0,07\end{array}$ \\
\hline $30 \mathrm{MPa}$ & $\begin{array}{c}\mathrm{a} / \mathrm{c}=0,52 \\
\mathrm{C}_{\text {água }}=205\end{array}$ & $\mathrm{C}_{\mathrm{cim}}=394$ & $\begin{array}{l}V_{c-p 1}=0,45 \\
V_{c-p 2}=0,30\end{array}$ & $\begin{array}{l}\mathrm{V}_{\mathrm{m}-\mathrm{a} 1}=0,21 \\
\mathrm{~V}_{\mathrm{m}-\mathrm{a} 2}=0,07\end{array}$ \\
\hline $40 \mathrm{MPa}$ & $\begin{array}{c}\mathrm{a} / \mathrm{c}=0,42 \\
\mathrm{C}_{\text {água }}=205\end{array}$ & $\mathrm{C}_{\mathrm{cim}}=489$ & $\begin{array}{l}\mathrm{V}_{\mathrm{c}-\mathrm{p} 1}=0,45 \\
\mathrm{~V}_{\mathrm{c}-\mathrm{p} 2}=0,30\end{array}$ & $\begin{array}{l}\mathrm{V}_{\mathrm{m}-\mathrm{a} 1}=0,19 \\
\mathrm{~V}_{\mathrm{m}-\mathrm{a} 2}=0,07\end{array}$ \\
\hline
\end{tabular}

Nota: Legenda:
$a_{1}$ - agregado miúdo natural fino;
$\mathrm{a}_{2}$ - agregado miúdo natural grosso;
$\mathrm{p}_{1}$ - agregado graúdo natural; $\mathrm{e}$
$\mathrm{p}_{2}$ - agregado graúdo reciclado. 
Tabela 3 - Traços unitários, em massa, teor de argamassa seca, teor de umidade, teor pasta e consumo de cimento das misturas - estudo teórico

\begin{tabular}{|c|c|c|c|c|c|c|c|c|c|c|c|c|c|c|}
\hline \multirow[b]{2}{*}{ 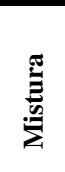 } & \multirow[b]{2}{*}{ 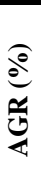 } & \multicolumn{6}{|c|}{ Traço unitário (em massa) } & \multirow[b]{2}{*}{$\mathbf{m}$} & \multirow[b]{2}{*}{$\underbrace{80}_{0}$} & \multirow[b]{2}{*}{$\underbrace{20}_{=}$} & \multirow[b]{2}{*}{$\underbrace{2}_{a}$} & \multirow[b]{2}{*}{$\underbrace{20}_{0}$} & \multirow{2}{*}{ 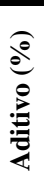 } & \multirow[b]{2}{*}{ 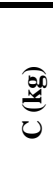 } \\
\hline & & c & $\mathbf{a}_{1}$ & $\mathbf{a}_{2}$ & $\mathbf{p}_{1}$ & $\mathbf{p}_{2}$ & $\mathbf{a} / \mathbf{c}$ & & & & & & & \\
\hline \multirow{3}{*}{ 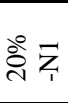 } & 18 & 1,00 & 1,02 & 0,34 & 1,89 & 0,41 & 0,42 & 3,7 & 50 & 8,9 & 35,9 & 11,1 & - & 476 \\
\hline & 18 & 1,00 & 1,42 & 0,47 & 2,34 & 0,51 & 0,52 & 4,7 & 51 & 9,1 & 32,8 & 12,8 & - & 385 \\
\hline & 18 & 1,00 & 1,74 & 0,58 & 2,70 & 0,59 & 0,60 & 5,6 & 50 & 9,1 & 31,1 & 15,9 & - & 333 \\
\hline \multirow{3}{*}{ 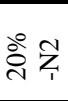 } & 18 & 1,00 & 0,96 & 0,32 & 1,84 & 0,40 & 0,42 & 3,5 & 51 & 9,3 & 36,8 & 11,4 & - & 489 \\
\hline & 18 & 1,00 & 1,35 & 0,45 & 2,28 & 0,49 & 0,52 & 4,6 & 50 & 9,3 & 33,7 & 13,1 & - & 394 \\
\hline & 18 & 1,00 & 1,66 & 0,55 & 2,63 & 0,57 & 0,60 & 5,4 & 50 & 9,4 & 31,9 & 16,3 & - & 342 \\
\hline \multirow{3}{*}{$\stackrel{\circ}{\stackrel{0}{8}}$} & 37 & 1,00 & 1,06 & 0,35 & 1,42 & 0,82 & 0,42 & 3,7 & 51 & 8,9 & 35,9 & 11,1 & - & 477 \\
\hline & 37 & 1,00 & 1,48 & 0,49 & 1,76 & 1,01 & 0,52 & 4,7 & 52 & 9,1 & 32,8 & 12,8 & - & 385 \\
\hline & 37 & 1,00 & 1,80 & 0,60 & 2,03 & 1,17 & 0,60 & 5,6 & 52 & 9,1 & 31,1 & 15,9 & - & 333 \\
\hline \multirow{3}{*}{ :̊ } & 37 & 1,00 & 1,00 & 0,33 & 1,38 & 0,80 & 0,42 & 3,5 & 52 & 9,3 & 36,8 & 11,4 & - & 489 \\
\hline & 37 & 1,00 & 1,40 & 0,46 & 1,71 & 0,99 & 0,52 & 4,6 & 51 & 9,3 & 33,7 & 13,1 & - & 394 \\
\hline & 37 & 1,00 & 1,71 & 0,57 & 1,98 & 1,14 & 0,60 & 5,4 & 51 & 9,4 & 31,9 & 16,3 & - & 342 \\
\hline
\end{tabular}

Nota: Legenda:

AGR - proporção final de agregado graúdo reciclado;

$\mathrm{a}_{1}$ - agregado miúdo natural fino;

$a_{2}$ - agregado miúdo natural grosso;

$\mathrm{p}_{1}$ - agregado graúdo natural;

$\mathrm{p}_{2}$ - agregado graúdo reciclado;

a/c - relação água-cimento;

$\mathrm{m}$ - teor de agregados secos;

a - teor de argamassa;

$\mathrm{H}$ - teor de água-materiais secos;

$\mathrm{P}$ - teor de pasta;

Vc - volume de cimento; e

C - consumo de cimento para $1 \mathrm{~m}^{3}$ de concreto.

Durante a etapa do estudo teórico da dosagem adotaram-se as seguintes considerações:

(a) os concretos foram dosados para três resistências de dosagem distintas - 25, 30 e 40

$\mathrm{MPa}$ - aos 28 dias de idade, de modo a obter no mínimo três pontos para o traçado das curvas de dosagem;

(b) para atender aos critérios de durabilidade preconizados pela NBR 6118 (ABNT, 2014), foi considerado que os concretos seriam aplicados em ambientes urbanos, classe de agressividade II;

(c) foi realizada uma adaptação da metodologia indicada para a determinação do consumo de água das misturas tendo em vista que o método recomenda a utilização do ensaio de abatimento do tronco de cone para medir a trabalhabilidade dos concretos. Entretanto, neste estudo a trabalhabilidade dos concretos reciclados foi medida pelo ensaio de espalhamento na mesa de Graff. Assim, os dois níveis de espalhamento adotados foram utilizados para determinação do consumo de água dos traços. Como base no estudo desenvolvido por Leite, Figueiredo Filho e Lima(2013), considerou-se que o nível de espalhamento N1 seria correspondente à faixa de abatimento de $60 \mathrm{~mm}$ a $80 \mathrm{~mm}$, e o nível de espalhamento N2 seria correspondente à faixa de abatimento de $80 \mathrm{~mm}$ a $100 \mathrm{~mm}$ para aplicação da tabela do método da ABCP que correlaciona faixa de abatimento com Dmax (dimensão máxima característica) do agregado graúdo na determinação do consumo de água; e

(d) o volume do agregado graúdo $(\mathrm{Vc})$ foi dividido entre os dois tipos de agregados graúdos utilizados no estudo (AGN e AGR) conforme o teor de AGR de cada família de concreto estudada.

É importante ressaltar que os valores encontrados na fase inicial de estudo da dosagem pelo método da $\mathrm{ABCP}$ representam apenas uma estimativa inicial das proporções dos concretos (Tabela 2 e Tabela 3). De acordo com Neville (2015), a determinação exata das proporções de uma mistura de concreto de maneira essencialmente teórica geralmente não é possível porque os materiais utilizados são, sobretudo, variáveis e porque diversas de suas propriedades não podem ser determinadas de maneira quantitativa. Em virtude disso, foi necessária a execução de misturas experimentais para a realização dos ajustes dos traços encontrados.

Também é importante ressaltar que os valores obtidos para $\mathrm{p}_{2}$ (proporção de AR em massa em relação à massa de cimento) não correspondem aos percentuais de $20 \%$ e $40 \%$ de p (proporção de 
agregado graúdo em massa em relação à massa de cimento), como previamente estabelecido. Isso ocorre porque no método da $\mathrm{ABCP}$ os traços são definidos em função do consumo de materiais, que, no caso dos agregados graúdos, é determinado em função de seu volume na composição de $1 \mathrm{~m}^{3}$ de agregados. Para o agregado graúdo especificamente, o consumo de agregado é obtido pelo produto entre o volume de agregado graúdo e sua massa unitária. Dessa forma, ocorreu redução do percentual de agregado graúdo reciclado utilizado no volume de concreto, uma vez que a massa unitária do AR é inferior à dos agregados naturais comumente usados na produção de concreto.

Os concretos foram produzidos utilizando-se uma betoneira de eixo inclinado com capacidade de 140 L. A sequência e o tempo de mistura foram realizados conforme estabelecido no método descrito por Tam, Gao e Tam (2005). O adensamento dos corpos de prova foi realizado em duas camadas, com o intuito de garantir maior compacidade para os concretos produzidos.

\section{Propriedades avaliadas}

A trabalhabilidade dos concretos foi medida através do ensaio de espalhamento na mesa de Graff, prescrito pela NBR NM 68 (ABNT, 1998). A resistência à compressão axial foi determinada de acordo com a NBR 5739 (ABNT, 2007a). Para cada mistura foram moldados 8 corpos de prova cilíndricos (200x100 mm), adensados e curados de acordo as prescrições da NBR 5738 (ABNT, 2007b).

\section{Resultados e discussões}

\section{Resultados da dosagem}

Durante realização do estudo experimental, observou-se que, inicialmente, as misturas apresentavam baixo teor de argamassa, mostrandose pouco homogêneas e sem coesão (Figura 2). O teor de argamassa dessas misturas foi alterado com o aumento do consumo de areia, tendo em vista que o método da ABCP utilizado fornece traços com baixos consumos de agregado miúdo (Tabela 3), sendo esses traços adotados como pontos de referência inicial para a realização das misturas experimentais. Entretanto, mesmo com o aumento do teor de argamassa e a melhoria do aspecto das misturas (Figura 3a), estas apresentavam tendência à exsudação, demonstrando o excesso de água nos concretos (Figura 3b). Além disso, verificou-se que os limites estabelecidos para o espalhamento foram superados em função da elevada fluidez. Adicionalmente, foi possível verificar também o excesso de pasta em algumas misturas produzidas. Optou-se então por reduzir o consumo de água e de cimento, mantendo fixa a relação a/c dessas misturas, uma vez que havia interesse em avaliar a resistência dos concretos com a relação a/c fornecida pelo método. A simples redução do consumo de água para reduzir o espalhamento iria modificar a relação a/c previamente estabelecida. Logo, a redução do teor de pasta reduziu a fluidez das misturas, além de reduzir também o consumo de cimento, o que pode resultar positivamente numa redução do custo de obtenção do concreto e no comportamento mecânico do concreto no estado endurecido.

Deve-se observar que durante o estudo de dosagem não foi realizada a modificação nos valores de $p$ através do aumento ou redução do consumo do agregado graúdo. Portanto, as reduções nos percentuais de agregado reciclado, apontadas anteriormente, foram mantidas. As proporções encontradas para cada uma das misturas, após o ajuste realizado no estudo experimental, estão apresentadas na Tabela 4.

A partir da análise da Tabela 4, é possível notar que houve aumento do teor ideal de argamassa proporcional ao aumento do percentual de agregado reciclado e do nível de espalhamento das misturas. Esses resultados já eram esperados em virtude das características do agregado reciclado, como forma irregular e textura rugosa, que provocam um efeito de travamento entre grãos do agregado e redução da mobilidade das misturas. Além disso, para uma mesma relação a/c, observase que o teor de água-materiais secos $(\mathrm{H} \%)$ das misturas também aumentou com o aumento do nível de espalhamento e o teor de AR dos concretos. Esse comportamento pode ser atribuído à elevada capacidade de absorção de água do material reciclado, que requer aumento no teor de água.

Como esperado, o aumento do teor de argamassa seca, para uma relação a/c fixa, resultou no aumento do consumo de cimento das misturas produzidas com maior teor de AR e maior nível de espalhamento. Verifica-se que, de modo geral, não foi necessária a utilização do aditivo superplastificante para que fosse alcançado o espalhamento desejado, exceto para a mistura com $\mathrm{f}_{\mathrm{cd}}$ de $40 \mathrm{MPa}$, com $40 \%$ de AGR-N2. 
Figura 2 - Falta de coesão observada no ensaio de espalhamento com traço inicial da mistura com $\mathrm{f}_{\mathrm{cd}}$ de 25MPa-20\%AGR-N1

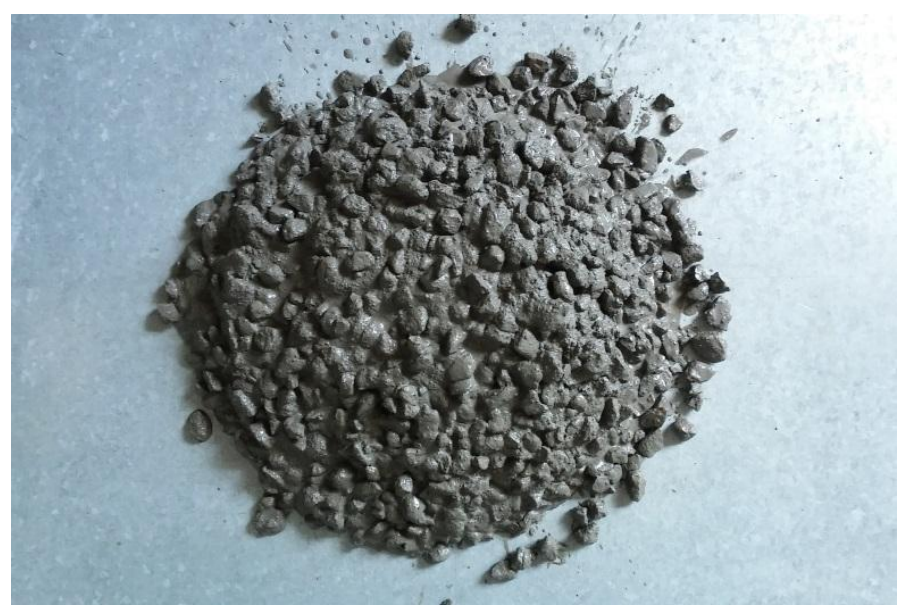

Figura 3 - Aspectos das misturas de concreto reciclado durante o estudo experimental após ajuste do teor de agregado miúdo - traço $f_{c d} 25 \mathrm{MPa}-20 \% A G R-N 2$

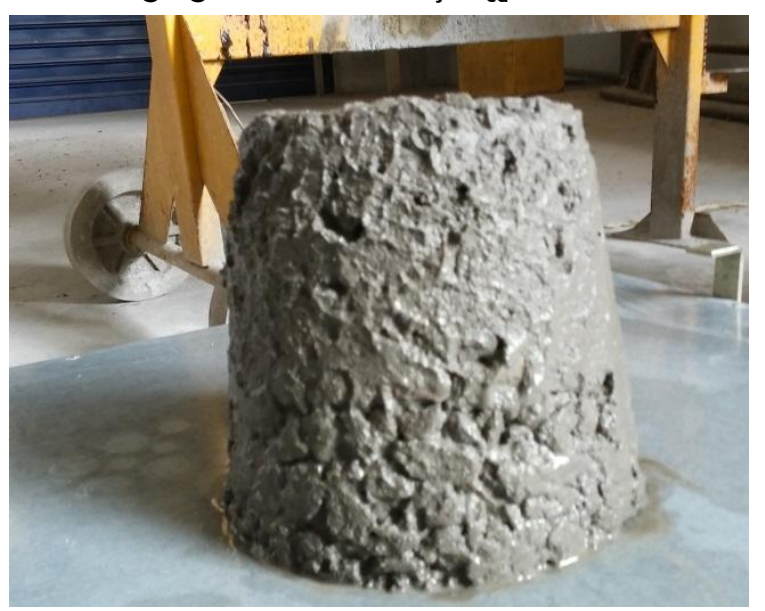

(a) Teor de argamassa inicial $=50 \%$

Foi possível notar que o método da $\mathrm{ABCP}$ (RODRIGUES, 1995), apesar de oferecer um estudo teórico inicial de fácil aplicação, proporcionou traços iniciais condicionados a tabelas e quadros que não contemplam a influência de algumas características qualitativas dos agregados, como forma, textura e capacidade de absorção, sobre as propriedades do concreto. E, por isso, as proporções incialmente encontradas nesse estudo teórico (Tabelas 2 e 3) apresentaram necessidade de grandes ajustes (Tabela 4). Além disso, a fixação da relação a/c com base na resistência e durabilidade dos concretos limitou sua adequação aos parâmetros de trabalhabilidade das misturas, no estado fresco. Dessa forma, podese inferir que, o trabalho dispensado aos ajustes dos traços obtidos no estudo teórico pode dificultar a aplicabilidade do método de dosagem da $\mathrm{ABCP}$

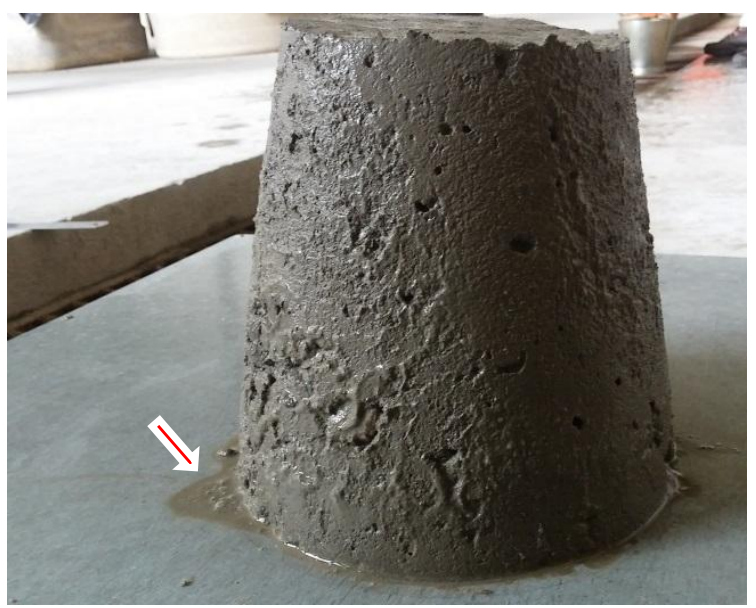

(b) Teor ideal de argamassa $=52 \%$, apresentando exsudação de água

(RODRIGUES, 1995) para a dosagem de concretos reciclados.

\section{Resultados de trabalhabilidade das misturas}

Os resultados de trabalhabilidade obtidos no presente estudo permitem demonstrar que o ensaio de espalhamento na mesa de Graff pode ser considerado como um bom parâmetro de controle da trabalhabilidade do concreto reciclado, visto que foi possível ajustar todas as misturas para atingirem as faixas estabelecidas sem que fosse necessário aumentar demasiadamente a quantidade de água efetiva delas. Nesse ensaio, a energia de vibração imposta ao material reduz o atrito interno e a viscosidade das misturas, aumentando sua mobilidade. Isso evidencia que o travamento provocado pela textura rugosa, pela forma mais 
irregular e pela maior absorção de água do agregado reciclado pode ser minimizado com a aplicação de um ensaio dinâmico. Como apontado por Leite (2001), na avaliação da trabalhabilidade de concretos reciclados, a introdução de uma componente dinâmica ao sistema de medição permite mensurar de modo mais adequado o comportamento desses concretos no estado fresco, o que reduz a interferência do atrito. Salienta-se ainda que, conforme observado por Leite, Figueiredo Filho e Lima (2013), assim como no ensaio de abatimento do tronco de cone, o equipamento utilizado para o ensaio de espalhamento na mesa de Graff pode ser considerado simples e de fácil manuseio, além de apresentar pouca influência do operador na obtenção dos resultados. Por isso é perfeitamente aplicável aos canteiros de obras.

Os resultados de espalhamento alcançados também podem ser atribuídos ao método de mistura utilizado na produção dos concretos. A redução da capacidade de absorção de água do agregado reciclado, consequência do procedimento de mistura em duas etapas proposto por Tam, Gao e Tam (2005), pode ter reduzido a influência negativa dessa característica sobre a trabalhabilidade das misturas. Além disso, para a mistura produzida com $40 \%$ de AGR para o nível de espalhamento $\mathrm{N} 2$, foi necessário o uso de aditivo superplastificante, que contribuiu para a melhoria da trabalhabilidade. A incorporação de aditivos redutores de água possibilita a desfloculação e a dispersão das partículas de cimento, o que melhora a fluidez das misturas e, assim, permite a liberação da água aprisionada em um sistema anteriormente floculado, e ainda fornece maior quantidade de água livre à mistura sem o aumento da relação a/c (NEVILLE, 2015). $\mathrm{O}$ uso de aditivos superplastificantes para a produção de concretos reciclados vem sendo apontado na literatura como uma forma eficiente para reduzir o efeito da maior taxa de absorção dos ARs sobre as propriedades dos concretos reciclados no estado fresco (SAFIUDDIN; ALENGARAM; SALAMB, 2011).

Tabela 4 - Traços unitários, em massa, teor de argamassa seca, teor de umidade, teor pasta e consumo de cimento das misturas - estudo experimental

\begin{tabular}{|c|c|c|c|c|c|c|c|c|c|c|c|c|c|c|c|}
\hline \multirow{2}{*}{ 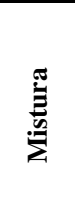 } & \multirow{2}{*}{$\frac{\sqrt{e}}{\frac{1}{5}}$} & \multicolumn{6}{|c|}{ Traço unitário (em massa) } & \multirow{2}{*}{$\mathbf{m}$} & \multirow{2}{*}{$\underbrace{8}_{\pi}$} & \multirow{2}{*}{$\underbrace{2}$} & \multirow{2}{*}{$\underbrace{2}_{a}$} & \multirow{2}{*}{$\underbrace{8}_{0}$} & \multirow{2}{*}{ 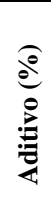 } & \multirow{2}{*}{$\underset{v}{\stackrel{\theta 00}{2}}$} & \multirow{2}{*}{ 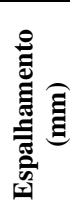 } \\
\hline & & c & $\mathbf{a}_{1}$ & $\mathbf{a}_{2}$ & $\mathbf{p}_{1}$ & $\mathbf{p}_{2}$ & $\mathbf{a} / \mathbf{c}$ & & & & & & & & \\
\hline \multirow{3}{*}{ 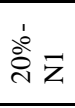 } & 18 & 1,00 & 1,10 & 0,36 & 1,93 & 0,42 & 0,42 & 3,8 & 51 & 8,8 & 35,0 & 15,5 & - & 464 & 350 \\
\hline & 18 & 1,00 & 1,73 & 0,56 & 2,57 & 0,56 & 0,52 & 5,4 & 51 & 8,1 & 30,0 & 11,7 & - & 351 & 360 \\
\hline & 18 & 1,00 & 2,08 & 0,69 & 2,94 & 0,64 & 0,60 & 6,4 & 51 & 8,1 & 28,5 & 10,2 & - & 305 & 355 \\
\hline \multirow{3}{*}{ 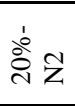 } & 18 & 1,00 & 1,04 & 0,34 & 1,81 & 0,39 & 0,42 & 3,6 & 52 & 9,1 & 36,4 & 16,1 & - & 483 & 385 \\
\hline & 18 & 1,00 & 1,48 & 0,49 & 2,28 & 0,49 & 0,52 & 4,7 & 52 & 9,1 & 32,8 & 12,8 & - & 385 & 395 \\
\hline & 18 & 1,00 & 1,95 & 0,65 & 2,70 & 0,58 & 0,60 & 5,9 & 52 & 8,7 & 30,0 & 10,7 & - & 322 & 415 \\
\hline \multirow{3}{*}{ 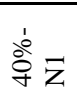 } & 37 & 1,00 & 1,13 & 0,37 & 1,42 & 0,82 & 0,42 & 3,7 & 53 & 8,9 & 35,3 & 15,6 & - & 469 & 345 \\
\hline & 37 & 1,00 & 1,77 & 0,59 & 1,87 & 1,08 & 0,52 & 5,3 & 53 & 8,3 & 30,3 & 11,8 & - & 355 & 340 \\
\hline & 37 & 1,00 & 2,17 & 0,72 & 2,16 & 1,25 & 0,60 & 6,3 & 53 & 8,2 & 28,6 & 10,2 & - & 306 & 370 \\
\hline \multirow{3}{*}{$\stackrel{8}{\stackrel{+}{+}}$} & 37 & 1,00 & 1,08 & 0,36 & 1,32 & 0,76 & 0,42 & 3,5 & 54 & 9,3 & 36,7 & 16,3 & 0,4 & 487 & 390 \\
\hline & 37 & 1,00 & 1,56 & 0,52 & 1,64 & 0,95 & 0,52 & 4,7 & 54 & 9,1 & 33,1 & 12,9 & - & 388 & 415 \\
\hline & 37 & 1,00 & 1,99 & 0,66 & 1,98 & 1,14 & 0,60 & 5,8 & 54 & 8,8 & 30,5 & 10,9 & - & 326 & 400 \\
\hline
\end{tabular}

Nota: Legenda:

AGR - proporção final de agregado graúdo reciclado;

$a_{1}$ - agregado miúdo natural fino;

$\mathrm{a}_{2}$ - agregado miúdo natural grosso;

$\mathrm{p}_{1}$ - agregado graúdo natural;

$\mathrm{p}_{2}$ - agregado graúdo reciclado;

a/c - relação água-cimento;

$\mathrm{m}$ - teor de agregados secos;

a - teor de argamassa;

$\mathrm{H}$ - teor de água-materiais secos;

$\mathrm{P}$ - teor de pasta;

Vc - volume de cimento; e

C - consumo de cimento para $1 \mathrm{~m}^{3}$ de concreto. 
Na Figura 4 pode ser visualizado o aspecto dos concretos durante a execução do ensaio de espalhamento na mesa de Graff. É possível verificar que as misturas apresentaram-se coesas e com pouca ou nenhuma segregação durante a realização do ensaio. Tais aspectos comprovam que os concretos apresentaram-se trabalháveis, uma vez que, como destacado por Figueirêdo Filho (2011), esse ensaio mostra-se mais sensível a questões relacionadas com a falta de coesão e segregação das misturas, quando estas possuem baixa ou muito baixa trabalhabilidade. Adicionalmente, foi possível observar que as misturas mantiveram-se homogêneas durante os procedimentos de lançamento e adensamento, apresentando ainda facilidade no processo de acabamento da superfície dos concretos.

A partir da análise visual dos concretos observouse ainda que as misturas plásticas (N1) com valores de espalhamento abaixo de $360 \mathrm{~mm}$ apresentaram uma tendência à manutenção da forma troncocônica, mostrando-se, aparentemente, menos homogêneas que as demais misturas. Apesar disso, não foi possível observar qualquer dificuldade para a execução do adensamento e acabamento dessas misturas.

\section{Resistência à compressão axial}

A Tabela 5 apresenta os resultados de resistência à compressão média, desvio padrão e coeficiente de variação dos concretos produzidos.
Os resultados mostram que, de um modo geral, as resistências de dosagem aos 28 dias foram alcançadas e que o aumento na relação a/c e no teor de agregados $\operatorname{secos}(\mathrm{m})$ promove redução da resistência, conforme observado por diversos autores (REIS, 2013; SEARA-PAZ et al., 2014; AMARIO, 2015; KOU; POON, 2015; entre outros).

\section{Diagramas de dosagem}

Como se pode observar na Tabela 4, os traços obtidos na etapa de ajuste do estudo experimental apresentaram, para dada mistura (mesmo teor de agregado reciclado e nível de espalhamento), o mesmo teor ideal de argamassa, compondo, portanto, uma mesma família de concretos (concretos produzidos com os mesmos materiais, mesmo teor de argamassa e mesma consistência). Assim, foi possível traçar para cada uma das famílias de concreto produzidas um diagrama de dosagem (Figuras 5 e 6 ).

A partir da análise dos diagramas de dosagem pode-se notar que nos concretos produzidos com $20 \%$ de AGR, para dada resistência à compressão aos 28 dias de idade, o aumento do nível de espalhamento resulta em um aumento do consumo de cimento por metro cúbico de concreto. É possível verificar, por exemplo, que misturas fluidas (N2) demandam um aumento de cerca de $10 \%$ no consumo de cimento para uma resistência média de $40 \mathrm{MPa}$, quando comparadas a misturas plásticas (N1). 
Figura 4 - Ensaio de espalhamento na mesa de Graff: a) 20\%AGR-N1; b) 20\%AGR-N2; b) 40\%AGR-N1; d) 40\%AGR-N2

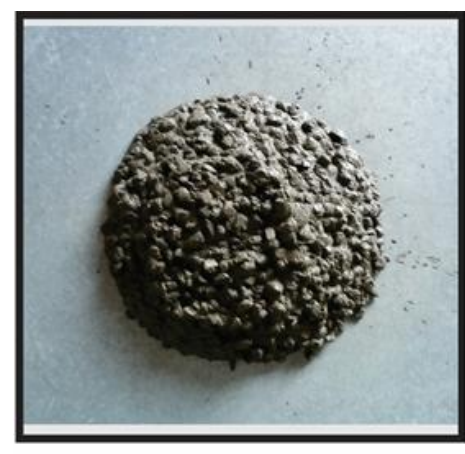

$20 \%$ AGR $-\mathrm{m}=3,8$

Espalhamento $=350 \mathrm{~mm}$

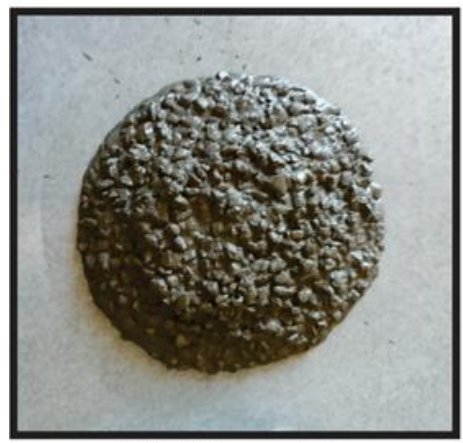

$20 \%$ AGR $-\mathrm{m}=3,6$

Espalhamento $=385 \mathrm{~mm}$

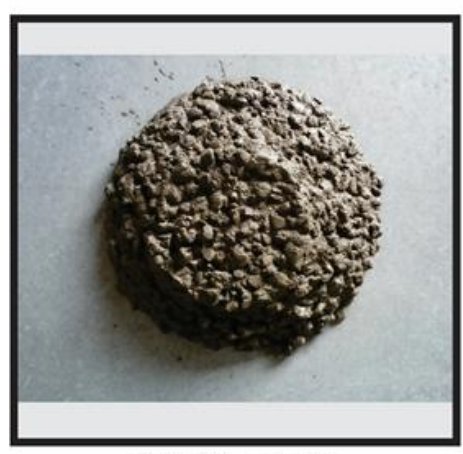

$40 \%$ AGR $-\mathrm{m}=3,7$

Espalhamento $=345 \mathrm{~mm}$

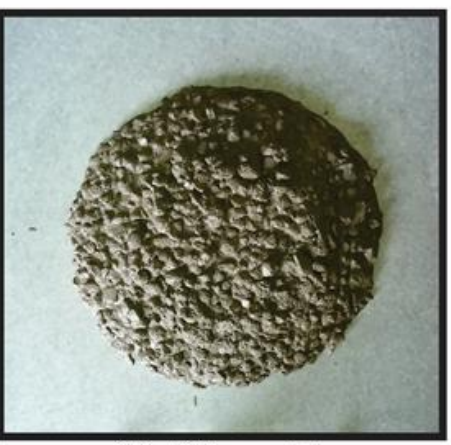

$40 \% \mathrm{AGR}-\mathrm{m}=3,5$

Espalhamento $=390 \mathrm{~mm}$

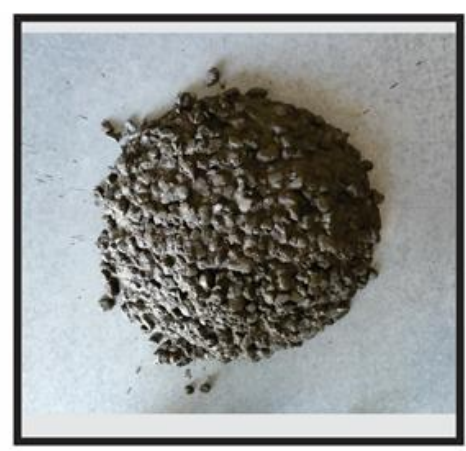

$20 \%$ AGR $-\mathrm{m}=5,4$

Espalhamento $=360 \mathrm{~mm}$

(a)

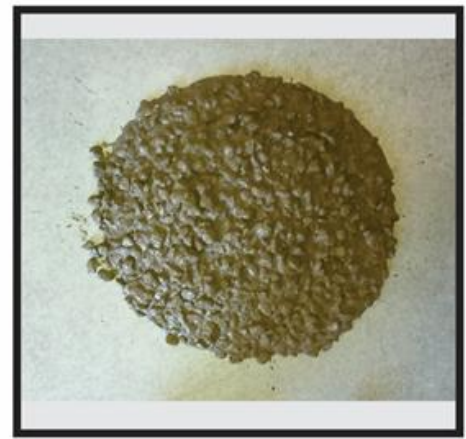

$20 \%$ AGR $-\mathrm{m}=4,7$

Espalhamento $=395 \mathrm{~mm}$

(b)

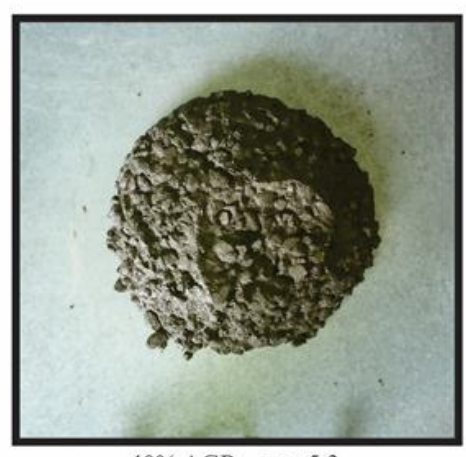

$40 \%$ AGR $-\mathrm{m}=5,3$

Espalhamento $=340 \mathrm{~mm}$

(c)

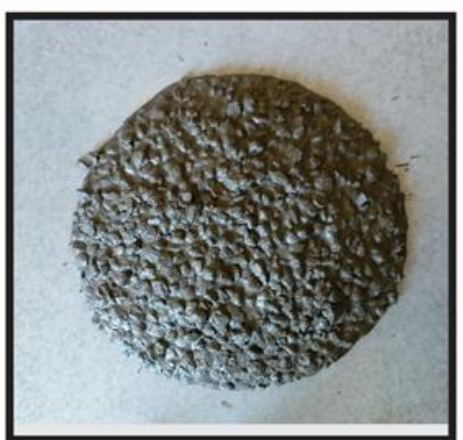

$40 \%$ AGR $-\mathrm{m}=4,7$

Espalhamento $=415 \mathrm{~mm}$

(d)

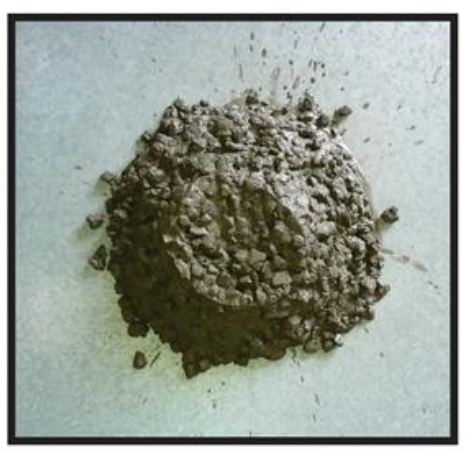

$20 \%$ AGR $-\mathrm{m}=6,4$

Espalhamento $=355 \mathrm{~mm}$

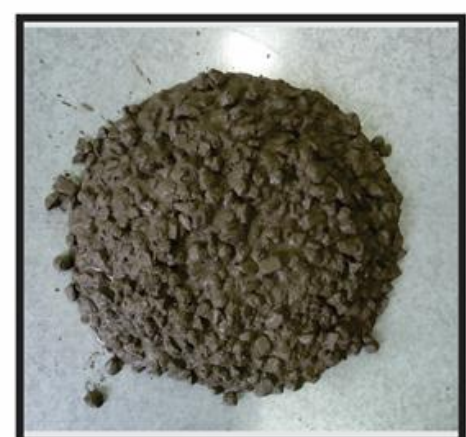

$20 \%$ AGR $-\mathrm{m}=5,9$

Espalhamento $=415 \mathrm{~mm}$

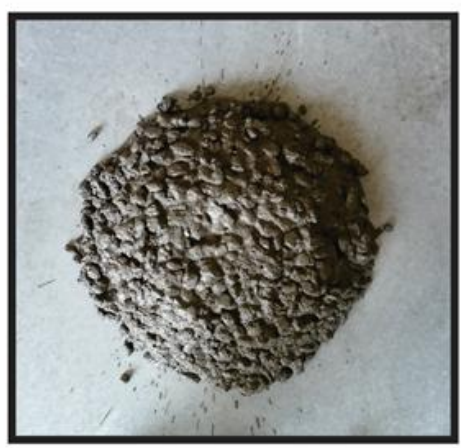

$40 \% \mathrm{AGR}-\mathrm{m}=6,3$

Espalhamento $=370 \mathrm{~mm}$

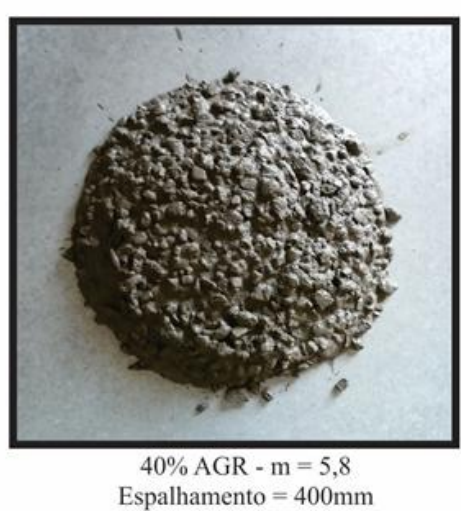


Tabela 5 - Resultados médios de resistência à compressão, desvio padrão e coeficiente de variação dos concretos produzidos pelo método $\mathrm{ABCP}$

\begin{tabular}{c|c|c|c|c}
\hline \multirow{2}{*}{ Mistura } & \multirow{2}{*}{ m } & \multirow{2}{*}{ a/c } & \multicolumn{2}{|c}{ fcm \pm Sd (CV) } \\
\cline { 4 - 5 } & & $\mathbf{7 ~ d i a s}$ & $\mathbf{2 8}$ dias \\
\hline \multirow{3}{*}{$20 \%-\mathrm{N} 1$} & 3,8 & 0,42 & $30,1 \pm 1,2(4,0)$ & $43,4 \pm 1,4(3,2)$ \\
& 5,4 & 0,52 & $25,8 \pm 1,3(5,1)$ & $35,1 \pm 1,5(4,3)$ \\
& 6,2 & 0,60 & $20,6 \pm 0,4(2,1)$ & $26,5 \pm 0,8(3,0)$ \\
\hline \multirow{3}{*}{$20 \%-\mathrm{N} 2$} & 3,6 & 0,42 & $34,8 \pm 0,5(1,4)$ & $41,6 \pm 1,2(2,8)$ \\
& 4,8 & 0,52 & $27,1 \pm 1,2(4,5)$ & $33,4 \pm 0,4(1,2)$ \\
& 5,9 & 0,60 & $21,7 \pm 0,1(0,6)$ & $25,9 \pm 1,1(4,3)$ \\
\hline \multirow{3}{*}{$40 \%-\mathrm{N} 1$} & 3,7 & 0,42 & $27,9 \pm 1,5(5,2)$ & $39,3 \pm 0,6(1,5)$ \\
& 5,3 & 0,52 & $25,8 \pm 0,7(2,6)$ & $30,2 \pm 1,0(3,2)$ \\
& 6,3 & 0,60 & $22,0 \pm 0,7(3,4)$ & $28,5 \pm 1,1(3,9)$ \\
\hline \multirow{3}{*}{$40 \%-\mathrm{N} 2$} & 3,5 & 0,42 & $32,9 \pm 0,9(2,7)$ & $44,9 \pm 1,2(2,7)$ \\
& 4,7 & 0,52 & $27,3 \pm 0,2(0,6)$ & $33,8 \pm 0,8(2,4)$ \\
& 5,8 & 0,60 & $23,0 \pm 0,9(3,9)$ & $27,6 \pm 0,9(3,2)$ \\
\hline
\end{tabular}

Figura 5 - Diagrama de dosagem das misturas produzidas com $20 \%$ de AGR

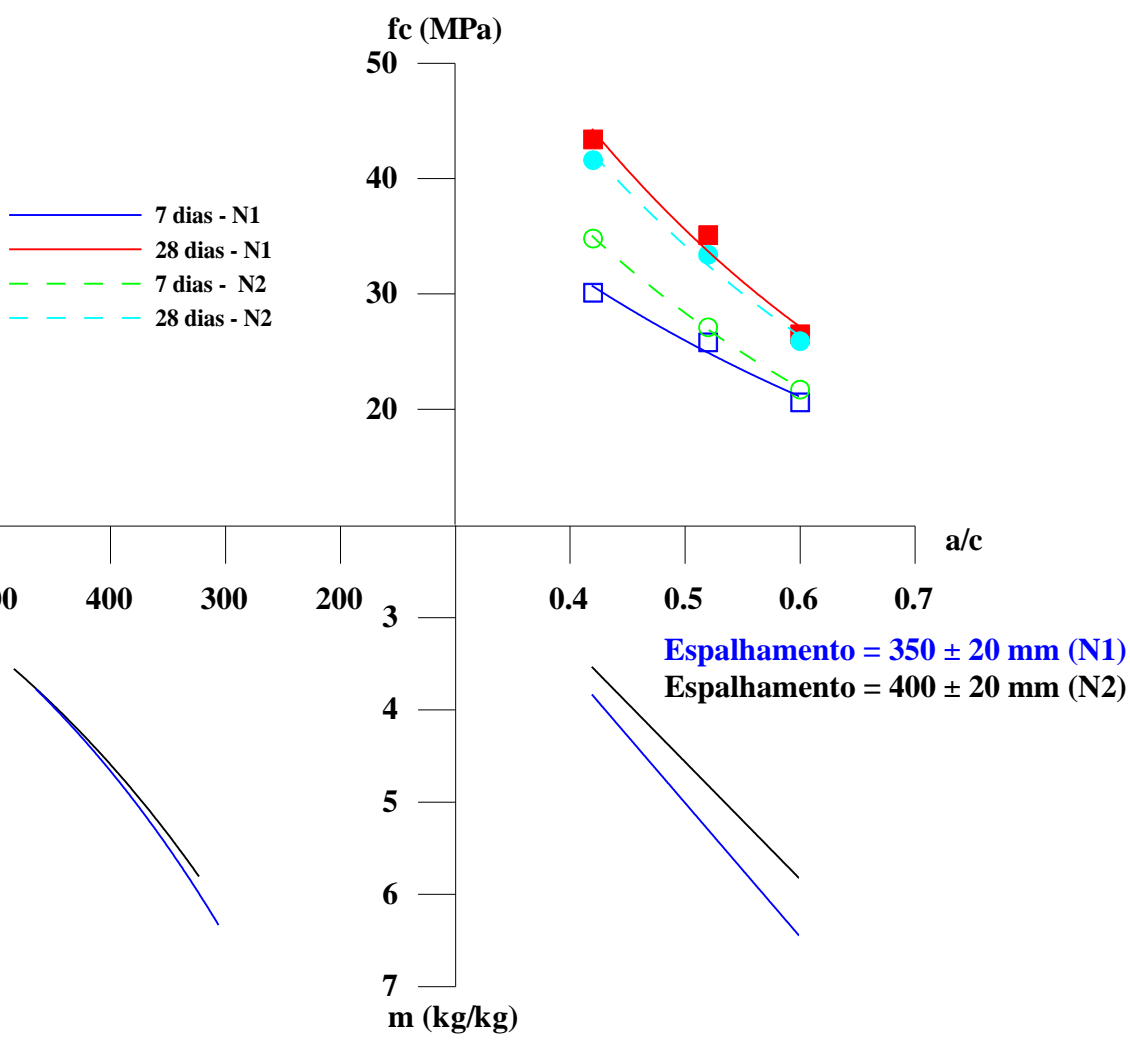


Figura 6 - Diagrama de dosagem das misturas produzidas com $40 \%$ de AGR

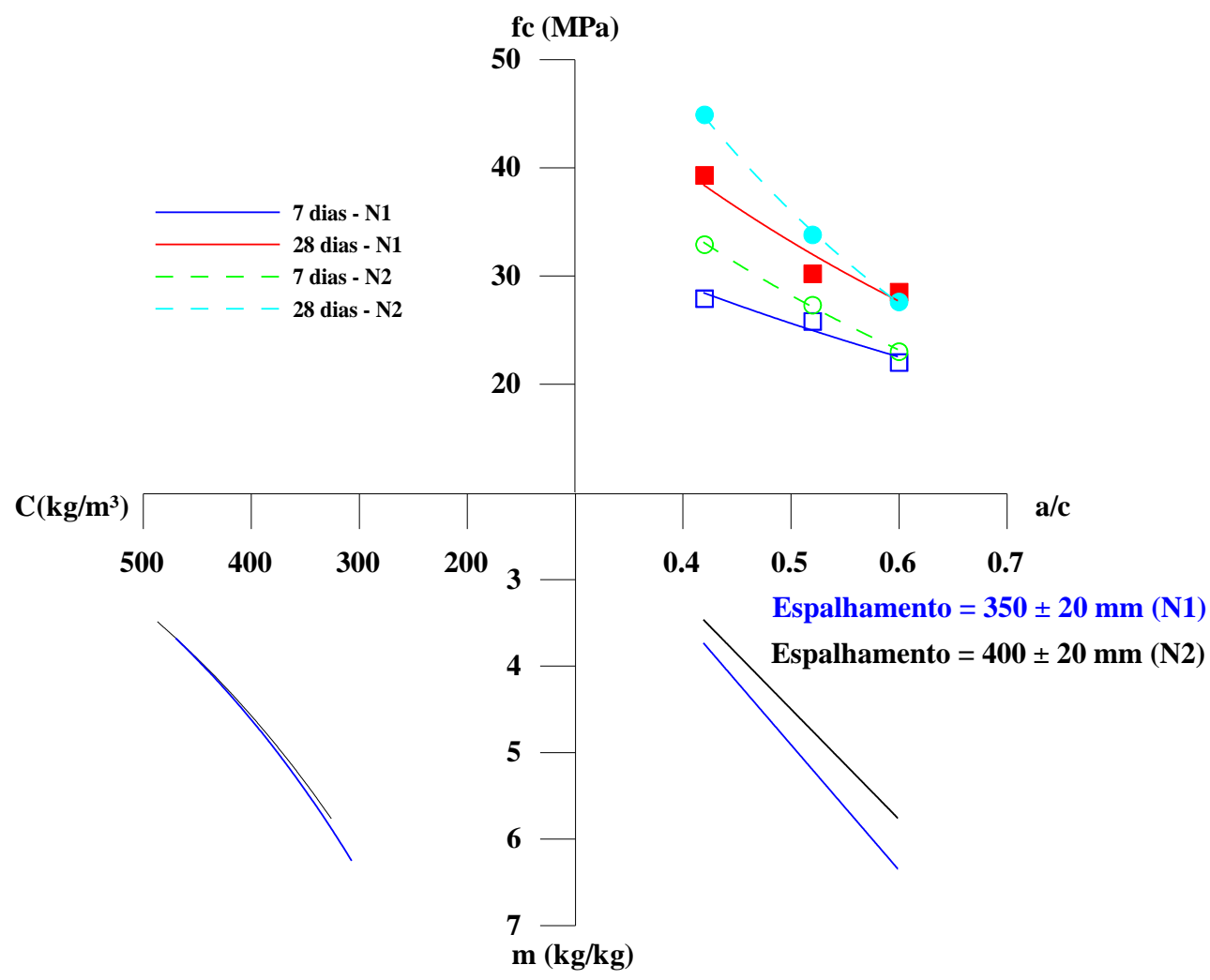

A Tabela 6 apresenta as equações retiradas da dosagem (leis de comportamento) a partir dos resultados experimentais alcançados neste estudo. Observa-se que as equações obtidas apresentam elevados coeficientes de determinação, o que demonstra sua capacidade de estimar resultados de dosagem, considerando que sejam mantidos os materiais e as características de produção dos concretos.

Os resultados mostram que, para concretos produzidos com $40 \%$ de agregado reciclado, misturas com maior valor de espalhamento $(400 \pm 20 \mathrm{~mm})$ demandam menor consumo de cimento para uma mesma resistência à compressão aos 28 dias. Esse comportamento pode influenciar positivamente as propriedades do concreto, uma vez que permite a produção de misturas mais fluidas, proporcionando melhor adensamento e, consequentemente, melhoria das propriedades do concreto no estado endurecido sem o aumento do custo final da mistura. Todavia, é importante notar que nesse caso a diferença entre os consumos de cimento para misturas com diferentes níveis de espalhamento tende a ser atenuada quando comparada com as diferenças obtidas nas misturas produzidas com 20\% de AGR. Diferentemente, Lovato et al. (2012) observaram aumentos nos consumos de cimento para concretos com $100 \%$ de agregados graúdos reciclados e níveis de resistência à compressão maiores ou iguais a 20 $\mathrm{MPa}$.

\section{Análise estatística}

Os resultados de resistência à compressão apresentados na Tabela 5 foram submetidos a análise estatística por meio da análise de variância (ANOVA). As variáveis analisadas estatisticamente foram teor de AGR, nível de espalhamento, relação a/c e idade. Os resultados da análise estatística demonstraram que a resistência à compressão foi significativamente influenciada pela idade (Figura 7). Como observado, quanto maior o grau de hidratação, maior a resistência à compressão dos concretos.

A relação a/c também exerceu influência significativa sobre os resultados de resistência à compressão, observando-se redução da resistência dos concretos com o aumento da relação a/c (Figura 7), conforme estabelecido pela Lei de Abrams. Quanto maior a relação a/c, maior a porosidade tanto da matriz, quanto da ligação entre a nova matriz de cimento e os agregados (reciclado e natural) presentes na composição dos concretos, e, assim, ocorrerá diminuição da resistência mecânica (LEITE, 2001; OTSUKI et al., 2003). 
Tabela 6 - Equações de dosagem obtidas para os concretos produzidos

\begin{tabular}{|c|c|c|c|c|}
\hline \multirow{2}{*}{ Concreto } & \multicolumn{2}{|c|}{ Lei de Abrams } & \multirow{2}{*}{ Lei de Lyse } & \multirow{2}{*}{ Lei de Molinari } \\
\hline & 7 dias & 28 dias & & \\
\hline 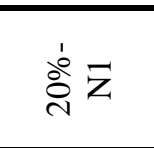 & $\begin{array}{c}\mathrm{fc}_{7}=\frac{73,432}{8,037^{\frac{\mathrm{a}}{\mathrm{c}}}} \\
\mathrm{r}^{2}=0,970830\end{array}$ & $\begin{array}{c}\mathrm{fc}_{28}=\frac{138,259}{15,105^{\frac{\mathrm{a}}{\mathrm{c}}}} \\
\mathrm{r}^{2}=0,979291\end{array}$ & $\begin{array}{c}\mathrm{m}=14,508 * \frac{\mathrm{a}}{\mathrm{c}}-2,248 \\
\mathrm{r}^{2}=0,995330\end{array}$ & $C=\frac{1000}{0,736+0,375 * m}$ \\
\hline 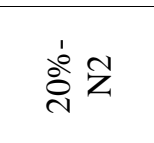 & $\begin{array}{l}\mathrm{fc}_{7} \frac{104,918}{13,722^{\frac{\mathrm{a}}{\mathrm{c}}}} \\
\mathrm{r}^{2}=0,999099\end{array}$ & $\begin{array}{c}\mathrm{fc}_{28}=\frac{126,361}{13,667^{\frac{\mathrm{a}}{\mathrm{c}}}} \\
\mathrm{r}^{2}=0,988722\end{array}$ & $\begin{array}{c}\mathrm{m}=12,705 * \frac{\mathrm{a}}{\mathrm{c}}-1,789 \\
\mathrm{r}^{2}=0,992072\end{array}$ & $C=\frac{1000}{0,970+0,345 * m}$ \\
\hline 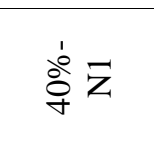 & $\begin{aligned} & \mathrm{fc}_{7}=\frac{48,891}{3,662^{\frac{\mathrm{a}}{\mathrm{c}}}} \\
& \mathrm{r}^{2}=0,934603\end{aligned}$ & $\begin{array}{c}\mathrm{fc}_{28}=\frac{82,314}{6,172^{\frac{\mathrm{a}}{\mathrm{c}}}} \\
\mathrm{r}^{2}=0,918470\end{array}$ & $\begin{array}{c}\mathrm{m}=14,508 * \frac{\mathrm{a}}{\mathrm{c}}-2,348 \\
\mathrm{r}^{2}=0,995330\end{array}$ & $C=\frac{1000}{0,730+0,379 * m}$ \\
\hline$\stackrel{+}{\stackrel{1}{e}} \mathrm{Z}$ & $\begin{aligned} & \mathrm{fc}_{7}=\frac{75,965}{7,272^{\frac{\mathrm{a}}{\mathrm{c}}}} \\
& \mathrm{r}^{2}=0,998436\end{aligned}$ & $\begin{array}{c}\mathrm{fc}_{28}=\frac{139,521}{15,014^{\frac{\mathrm{a}}{\mathrm{c}}}} \\
\mathrm{r}^{2}=0,998968\end{array}$ & $\begin{array}{c}\mathrm{m}=12,746 * \frac{\mathrm{a}}{\mathrm{c}}-1,876 \\
\mathrm{r}^{2}=0,998482\end{array}$ & $C=\frac{1000}{0,977+0,338 * m}$ \\
\hline
\end{tabular}

Nota: Legenda:

$$
\begin{aligned}
& \text { fc - resistência média à compressão }(\mathrm{MPa}) \text {; } \\
& \text { a/c - relação água-cimento; } \\
& \mathrm{m} \text { - teor de agregados secos; e } \\
& \mathrm{c} \text { - consumo de cimento }\left(\mathrm{kg} / \mathrm{m}^{3}\right) \text {. }
\end{aligned}
$$

Figura 7- Influência do efeito significativo da idade sobre os resultados de resistência à compressão dos concretos para diferentes relações a/c: a) misturas com $20 \%$ de AGR; b) misturas com $40 \%$ de AGR

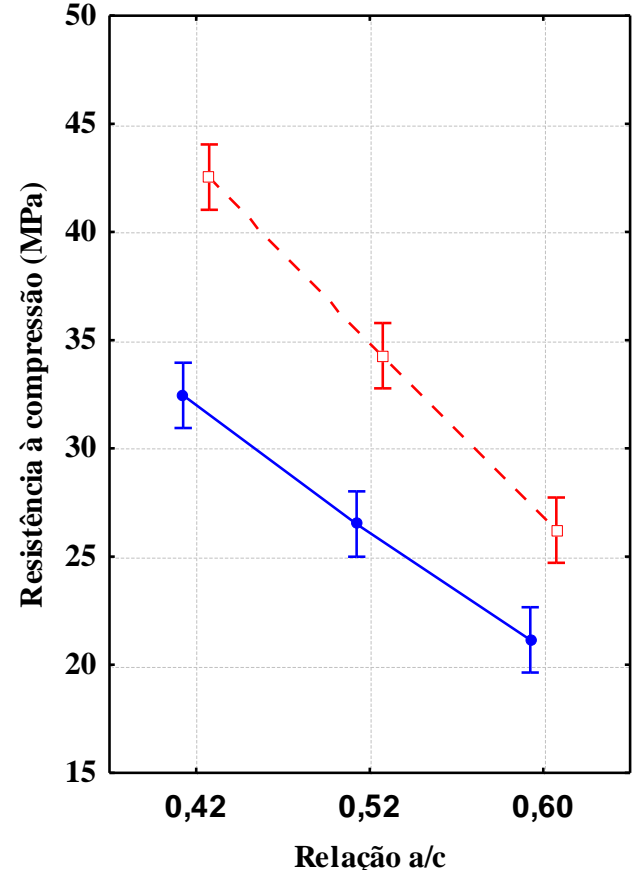

(a)

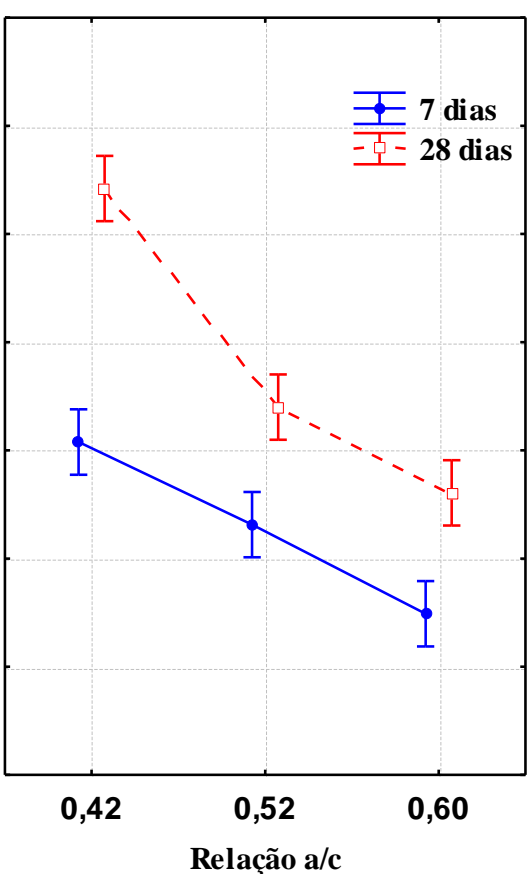

(b)
Além disso, o fator nível de espalhamento influenciou de forma significativa a resistência à compressão dos concretos. A Figura 8 mostra uma tendência para o melhor comportamento mecânico das misturas com maior nível de espalhamento. Como discutido anteriormente, as misturas foram produzidas com a mesma relação a/c, independentemente do nível de espalhamento. Esse aumento da resistência à compressão nas misturas com maior nível de espalhamento (N2) pode ser atribuído a alguns fatores, como:

(a) maior teor de argamassa, que, sem a influência negativa de um aumento da relação a/c, foi responsável pela maior resistência à compressão 
apresentada pelas misturas com maior nível de espalhamento. O ganho de resistência dos concretos, em função de um maior teor de argamassa, também pode ser observado no trabalho de Fathifazl et al. (2009);

(b) maior dispersão das partículas de cimento apresentada por misturas mais fluidas (nível de espalhamento $\mathrm{N} 2=400 \pm 20 \mathrm{~mm}$ ), o que acarreta em maior desenvolvimento da quantidade de produtos resistentes e, assim, na melhoria da resistência final. De acordo com Neville (2015), a dispersão dos grãos de cimento permite a exposição de uma maior área superficial da partícula à hidratação, proporcionando aumento da resistência do concreto;

(c) uso do agregado reciclado seco, que, associado ao método de mistura em duas etapas, contribuiu para melhorar a ligação matrizagregado pela formação de uma película de pasta na superfície dos grãos de AR. Melhorias na zona de transição e aumento na resistência à compressão de concretos reciclados, como consequência do uso do método de mistura em duas etapas, também foram apontados por Li et al.(2012) e por Leite e Monteiro (2016);

(d) menor proporção de agregados graúdos nas misturas $(\mathrm{p}=\mathrm{p} 1+\mathrm{p} 2)$ em função do aumento do teor de argamassa, o que deve ter contribuído para aumentar a compacidade dos concretos; e

(e) uso de um agregado reciclado de concreto, que apresenta menor porosidade que um agregado cerâmico e, assim, melhores propriedades do grão, conforme observado por Yang, Du e Bao (2011), Reis (2009), Cabral (2007), Fonseca (2006) e Leite (2001), bem como uso desse agregado na condição seca, o que contribui para a redução da relação a/c na matriz e na ligação matriz-agregado devido à absorção de água pelo grão do agregado.

Verificou-se também que o teor de AR na proporção das misturas não apresentou influência na resistência à compressão dos concretos. Desse modo, considerando o uso do método da ABCP adaptado e a forma de produção utilizada neste estudo, foi possível utilizar até $40 \%$ de AGR de concreto para produção de novos concretos tendo sido alcançados os níveis de resistência à compressão estabelecidos para a dosagem (25 $\mathrm{MPa}, 30 \mathrm{MPa}$ e $40 \mathrm{MPa}$ ). Os concretos reciclados produzidos apresentam melhoria da densidade das misturas, que é resultado do método de mistura utilizado, da melhoria na ligação da nova matriz de pasta de cimento e os agregados, e das características do AR empregado, como a menor fragilidade do grão, por exemplo, e a redução da relação a/c das matrizes de cimento, uma vez que o agregado foi usado na condição seca. Assim, o uso de baixos teores de agregado reciclado pode ter compensado o efeito prejudicial da incorporação desse material, que geralmente é mais poroso que os agregados naturais, na resistência à compressão dos concretos, como é comumente apontado na literatura (FERREIRA; BRITO; BARRA, 2011; BRAVO et al., 2015; CEIA et al., 2016).

Figura 8 - Influência do efeito significativo do nível de espalhamento sobre os resultados de resistência à compressão dos concretos em diferentes idades

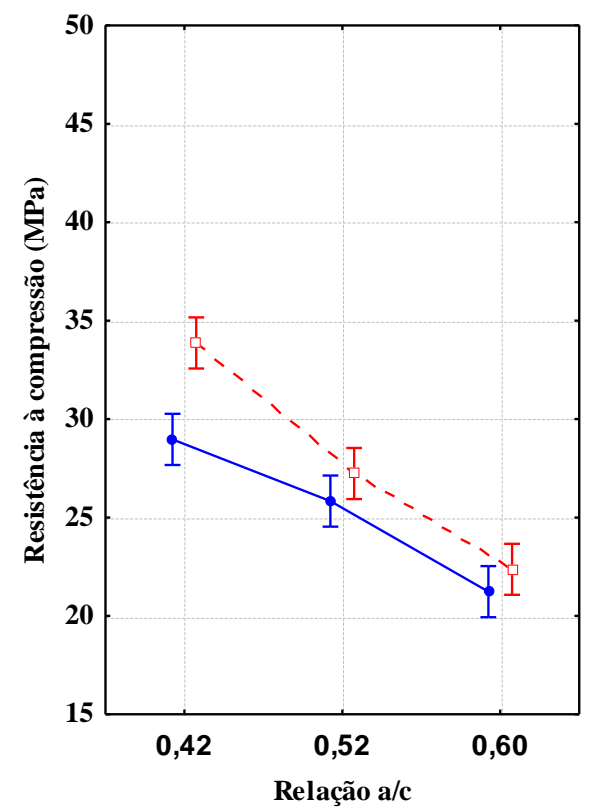

(a) 7 dias

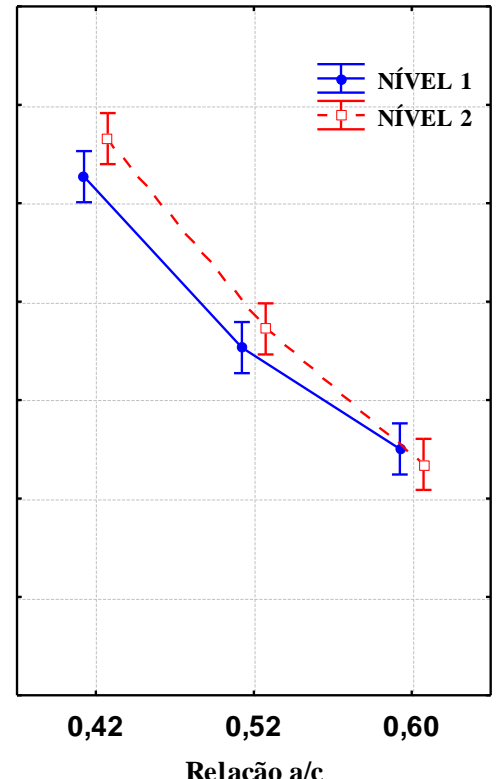

(b) 28 dias 


\section{Conclusões}

O estudo mostrou que a obtenção das misturas de concreto produzidas com AR utilizando o método de dosagem da $\mathrm{ABCP}$ apresentou necessidade de maior trabalho dispensado aos ajustes experimentais dos traços. Conforme preconiza o método, foram obtidos traços iniciais de forma teórica que não contemplaram a influência de algumas características qualitativas dos agregados reciclados sobre as propriedades do concreto, como, por exemplo, sua textura mais rugosa, a forma mais irregular e maior taxa de absorção de água. Em virtude do grande esforço experimental realizado, considera-se mais adequado o uso de outros métodos que possibilitem avaliações experimentais mais diretas no processo de dosagem, como é caso do método do IPT/EPUSP ou do método do empacotamento compressível (MEC).

A adaptação do método da ABCP utilizando como medida de trabalhabilidade o espalhamento na mesa de Graff se mostrou satisfatório tendo em vista que, com os ajustes experimentais realizados, todas as misturas atingiram a faixa de espalhamento estabelecida sem que fosse necessário grande aumento da quantidade efetiva de água nas misturas, por exemplo. Além disso, os ajustes experimentais da dosagem permitiram a produção de concretos que alcançaram as resistências de dosagem aos 28 dias de idade previamente estabelecidas (25 $\mathrm{MPa}, 30 \mathrm{MPa}$ e 40 $\mathrm{MPa}$ ) para todas as famílias de concreto avaliadas (20\%-N1, 20\%-N2, 40\%-N1 e 40\%-N2). O uso do agregado reciclado nos teores de $20 \%$ e $40 \%$ da proporção de agregados das misturas de concreto acarretou um aumento do teor ideal de argamassa seca. Esse aumento foi maior com o aumento do teor de AR (40\%) e com o aumento do nível de espalhamento (N2).

Após uma análise estatística dos resultados experimentais, observou-se que a resistência à compressão dos concretos apresentou influência significativa do nível de espalhamento, sendo constatado melhor comportamento mecânico das misturas com maior nível de espalhamento $(\mathrm{N} 2=400 \pm 20 \mathrm{~mm})$. Por outro lado, o teor de agregado graúdo reciclado de concreto utilizado $(20 \%$ ou $40 \%)$ não apresentou influência significativa sobre os resultados de resistência à compressão obtidos. Isso mostra que a adoção de teores de AR menores ou iguais a $40 \%$, o uso de AR de concreto, que apresenta menor porosidade que outros tipos de agregados reciclados, e a aplicação de uma dosagem que incorpore o AR na proporção da mistura, entre outros fatores, podem contribuir de forma benéfica para a dosagem e ampliação da aplicação desse material na produção de concretos reciclados de melhor comportamento, tanto no estado fresco quanto no estado endurecido.

Assim, é importante ampliar o estudo de dosagem de concretos reciclados, avaliando outros métodos, outros níveis de trabalhabilidade, incorporando o teor de AR na proporção das misturas, e também ampliando a avaliação das propriedades, quer no estado fresco, quer no estado endurecido, dos concretos obtidos com essas dosagens.

\section{Referências}

AMARIO, M. Dosagem Científica de Concretos Estruturais Contendo Agregado de Resíduo de Concreto (ARC). Rio de Janeiro, 2015. $213 \mathrm{f}$. Dissertação (Mestrado em Engenharia Civil) Programa de Pós-Graduação em Engenharia Civil, Universidade Federal do Rio de Janeiro, Rio de Janeiro, 2015.

ANGUlO, S. C. Caracterização de Agregado de Resíduos de Construção e Demolição Reciclados e a Influência de Suas Características no Comportamento de Concretos. São Paulo, 2005. 167 f. Tese (Doutorado em Engenharia) - Escola Politécnica, Universidade de São Paulo, São Paulo, 2005.

ASSOCIAÇÃO BRASILEIRA DE NORMAS TÉCNICAS. NBR 5738: moldagem e cura de corpos-de-prova cilíndricos ou prismáticos de concreto. Rio de Janeiro, 2007b.

ASSOCIAÇÃO BRASILEIRA DE NORMAS TÉCNICAS. NBR 5739: concreto: ensaios de compressão de corpos-de-prova cilíndricos. Rio de Janeiro, 2007a.

ASSOCIAÇÃO BRASILEIRA DE NORMAS TÉCNICAS. NBR 6118: projeto de estruturas de concreto: procedimento. Rio de Janeiro, 2014.

ASSOCIAÇÃO BRASILEIRA DE NORMAS TÉCNICAS. NBR 7211: agregados para concreto: especificação. Rio de Janeiro, 2009.

ASSOCIAÇÃO BRASILEIRA DE NORMAS TÉCNICAS. NBR 7809: agregado graúdo: determinação do índice de forma pelo método do paquímetro: método de ensaio. Rio de Janeiro, $2006 \mathrm{~b}$

ASSOCIAÇÃO BRASILEIRA DE NORMAS TÉCNICAS. NBR NM 45: determinação da Massa Unitária. Rio de Janeiro, 2006a.

ASSOCIAÇÃO BRASILEIRA DE NORMAS TÉCNICAS. NBR NM 46: determinação do Material Pulverulento. Rio de Janeiro, 2003c. 
ASSOCIAÇÃO BRASILEIRA DE NORMAS TÉCNICAS. NBRNM 51: agregado graúdo: ensaio de abrasão "Los Angeles". Rio de Janeiro, 2001.

\section{ASSOCIAÇÃO BRASILEIRA DE NORMAS} TÉCNICAS. NBR NM 53: agregado graúdo: determinação da massa específica, massa específica aparente e absorção de água. Rio de Janeiro, 2003b.

\section{ASSOCIAÇÃO BRASILEIRA DE NORMAS} TÉCNICAS. NBR NM 68: concreto: determinação da consistência pelo espalhamento na mesa de Graff. Rio de Janeiro, 1998.

\section{ASSOCIAÇÃO BRASILEIRA DE NORMAS} TÉCNICAS. NBR NM 248: determinação da Composição Granulométrica. Rio de Janeiro, 2003a.

BAIRAGI, N. K.; VIDYADHARA, H. S.; RAVANDE, K. Mix Design Procedure For Recycled Aggregate Concrete. Construction \& Building Materials, v. 4, n. 4, p. 188- 193, 1990.

BRAVO, M. et al. Mechanical Performance of Concrete Made With Aggregates From Construction and Demolition Waste Recycling Plants. Journal of Cleaner Production,v. 99, p. 59-74, 2015.

BRITO, J. Agregados Reciclados e Sua Influência nas Propriedades dos Betões.Lição de Síntese, Provas de Agregação em Engenharia Civil, Instituto Superior Técnico, Lisboa, 2005.

CABRAL, A. E. B. Modelagem de Propriedades Mecânicas e de Durabilidade de Concretos Produzidos Com Agregados Reciclados, Considerando-se a Variabilidade da Composição do RCD. São Carlos, 2007. 254 f. Tese (Doutorado em Ciências da Engenharia Ambiental) - Escola de Engenharia de São Carlos, Universidade de São Paulo, São Carlos, 2007.

CAVALHEIRO, A.P. Contribuição Para a Implementação de Agregado Reciclado de Concreto em Uma Empresa de Pré-Fabricados de Concreto. São Leopoldo, 2011. $151 \mathrm{f}$. Dissertação (Mestrado em Engenharia Civil) Programa de Pós-Graduação em Engenharia Civil, Universidade do Vale do Rio dos Sinos, São Leopoldo, 2011.

CEIA, F. et al. Shear Strength of Recycled Aggregate Concrete to Natural Aggregate Concrete Interfaces. Construction and Building Materials, v. 109, p. 139-145, 2016.
FATHIFAZL, G. et al. New Mixture

Proportioning Method For Concrete Made With Coarse Recycled Concrete Aggregate. Journal of Materials in Civil Engineering, v. 21, p. 601611, 2009.

FERREIRA, L. M. M. Betões Estruturais Com Incorporação de Agregados Grossos Reciclados de Betão: influência da pré-saturação. Lisboa, 2007. 144 f. Dissertação (Mestrado em Engenharia Civil) - Instituto Superior Técnico, Universidade Técnica de Lisboa, Lisboa, 2007.

FERREIRA, L.; BRITO, J.; BARRA, M. Influence of the Pre Saturation of Recycled Coarse Concrete Aggregates on Concrete Properties. Magazine of Concrete Research,v. 63, n. 8, p. 617-627, 2011.

FIGUEIRÊDO FILHO, J. G.L. Avaliação da Trabalhabilidade de Concreto Contendo Agregado Reciclado de Argamassa. Feira de Santana, 2011. 89 f. Dissertação (Mestrado em Engenharia Civil e Ambiental) - Programa de PósGraduação em Engenharia Civil e Ambiental, Universidade Estadual de Feira de Santana, Feira de Santana, 2011.

FONSECA, A. P. Estudo Comparativo de Concretos Com Agregado Graúdo Reciclado de Telha Cerâmica e Agregado Graúdo Natural. Uberlândia, 2006. 200 f. Dissertação (Mestrado em Engenharia Civil) - Programa de Pós-Graduação em Engenharia Civil, Universidade Federal de Uberlândia, Uberlândia, 2006.

FONSECA, N.; BRITO, J.; EVANGELISTA, L. The Influence of Curing Conditions on the Mechanical Performance of Concrete Made With Recycled Concrete Waste. Cement \& Concrete Composites, v. 33, p. 637-643, 2011.

GONÇALVES, M. S. Análise da Viabilidade Técnica de Utilização de Resíduos de Concreto Oriundos da Pré-Fabricação Como Agregado Graúdo Para a Produção de Novos Concretos. São Leopoldo, 2011. 116 F. Dissertação (Mestrado em Engenharia Civil) - Programa de PósGraduação em Engenharia Civil, Universidade do Vale do Rio dos Sinos, São Leopoldo, 2011.

GONZÁLEZ-FONTEBOA, B. et al.Structural Recycled Concrete: behaviour under low loading rate. Construction and Building Materials,v. 28, p. 111-116, 2012.

KOU, S.; POON, C. Effect of the Quality of Parent Concrete on the Properties of High Performance Recycled Aggregate Concrete. Construction and Building Materials, v. 77, p. 501-508, 2015. 
KWAN, W. H. et al. Influence of the Amount of Recycled Coarse Aggregate in Concrete Design and Durability Properties. Construction and Building Materials, v. 26, p. 565-573, 2012.

JORDANI, B. Estudo do Agregado Graúdo Reciclado de Concreto Como Agente de Cura Interna em Concreto Com Cinza de Casca de Arroz. São Leopoldo, 2016. 107 f. Dissertação (Mestrado em Engenharia Civil) - Programa de Pós-Graduação em Engenharia Civil, Universidade do Vale do Rio dos Sinos, São Leopoldo, 2016.

LEITE, M.B. Avaliação de Propriedades Mecânicas de Concretos Produzidos com Agregados Reciclados de Resíduos de Construção e Demolição. Porto Alegre, 2001. 270p. Tese (Doutorado em Engenharia Civil) Programa de Pós-Graduação em Engenharia Civil, Universidade Federal do Rio Grande do Sul, Porto Alegre, 2001.

LEITE, M. B.; FIGUEIREDO FILHO, J. G. L.; LIMA, P. R. L. Workability Study of Concretes Made With Recycled Mortar Aggregate. Materials and Structure, v. 46, n. 10, p. 1765-1778, 2013.

LEITE, M. B.; MONTEIRO, P. J. M.

Microstructural Analysis of Recycled Concrete Using X-ray Microtomography. Cement and Concrete Research, v. 81, p. 38-48, 2016.

LI, W. et al. Interfacial Transition Zones Inrecycled Aggregate Concrete With Different Mixing Approaches. Construction and Building Materials, v. 35, p. 1045-1055, 2012.

LOVATO, P. S. et al. Modeling of Mechanical Properties and Durability of Recycled Aggregate concretes. Construction and Building Materials, v. 26, p. 437-447, 2012.

MALTA, J. O. Dosagem de Concretos Produzidos Com Agregado Miúdo Reciclado de Resíduo de Construção e Demolição. Salvador, 2012. 177 f. Dissertação (Mestrado em Engenharia Ambiental Urbana) - Escola de Engenharia, Universidade Federal da Bahia, Salvador, 2012.

MATIAS, D. et al. Mechanical Properties of Concrete Produced With Recycled Coarse Aggregates: influence of the use of superplasticizers. Construction and Building Materials, v. 44, p. 101-109, 2013.

MOITINHO, B. L. R; LEITE, M. B. Estudo da Produção de Concretos Reciclados Utilizando Agregados de Argamassa. In: ENCONTRO NACIONAL SOBRE REAPROVEITAMENTO DE RESÍDUO NA CONSTRUÇÃO CIVIL, 4., São Paulo, 2015. Anais... São Paulo: USP, 2015.
MOREIRA, L. H. H. Avaliação da Influência da Origem e do Tratamento dos Agregados Reciclados de Resíduos de Construção e Demolição no Desempenho Mecânico do Concreto Estrutural. São Paulo, 2010. 92 f. Dissertação (Mestrado em Engenharia Civil) Programa de Pós-Graduação em Engenharia Civil, Escola Politécnica, Universidade de São Paulo, São Paulo, 2010.

NEVILLE, A. M. Propriedades do Concreto. 5. ed. Porto Alegre: Bookman, 2015.

NUNES, W. C. Influência do Agregado Graúdo Reciclado de Resíduos da Construção Predial nas Propriedades do Concreto Fresco e Endurecido. Goiânia, 2007. 200 f. Dissertação (Mestrado em Engenharia Civil) -Escola de Engenharia Civil, Universidade Federal de Goiás, Goiânia, 2007.

OTSUKI, N. et al.Developed Method for Measuring Flexural Strength and Modulus of Elasticity of Micro-Regions in Normal and Recycled Aggregate Concretes. Magazine of Concrete Research, v. 55, p. 439-448, 2003.

PACHECO-TORGAL, F.; JALALI, S. Reusing Ceramic Wastes in Concrete. Construction and Building Materials, v. 24, p. 832-838, 2010.

PADOVAN, R. G. Influência da Pré-Molhagem nas Propriedades de Concretos Produzidos Com Agregado Reciclado de Concreto. São Leopoldo, 2013. 155 f. Dissertação (Mestrado em Engenharia Civil) - Programa de Pós-Graduação em Engenharia Civil, Universidade do Vale do Rio dos Sinos, São Leopoldo, 2013.

POON, C. S. et al. Influence of Moisture States of Natural and Recycled Aggregates on the Slump and Compressive Strength of Concrete. Cement and Concrete Research, v. 34, p. 31-36, 2004.

RAHMAN, I. A.; HAMDAM, H.; ZAIDI, A. M. A. Assessment of Recycled Aggregate Concrete.Modern Applied Science, v. 3, n. 10, p. 47-54, 2009.

RAVINDRARAJAH, R. S.Utilization of Waste Concrete For New Construction.Conservorion e Recycling, v. 10, n. 213, p. 69-74, 1987.

REIS, C. N. S. Influência da Utilização de Agregado Miúdo de RCD na Aderência Açoconcreto Reciclado.Feira de Santana, 2009. 151 f. Dissertação (Mestrado em Engenharia Civil e Ambiental) - Programa de Pós-Graduação em Engenharia Civil e Ambiental, Universidade Estadual de Feira de Santana, Feira de Santana, 2009. 
REIS, F. J. L. Avaliação da Durabilidade de Concreto Produzido Com Agregados Graúdos Reciclados Provenientes de Cerâmica Vermelhas Com Diferentes Taxas de PréSaturação. Belém, 2013. 141 f. Dissertação (Mestrado em Engenharia Civil) - Programa de Programa de Pós-Graduação em Engenharia Civil, Universidade Federal do Pará, Belém, 2013.

RODRIGUES, P. P. F. Parâmetros de Dosagem do Concreto. 2. ed. São Paulo: ABCP, 1995.

RODRIGUES, C. R. S.; FUCALE, S. Dosagem de Concretos Produzidos Com Agregado Miúdo Reciclado de Resíduo da Construção Civil. Ambiente Construído, Porto Alegre, v. 14, n. 1, p. 99-111, 2014.

SAFIUDDIN, M. D.; ALENGARAM, U. J.; SALAMB, M. D. A. Properties of HighWorkability Concrete With Recycled Concrete Aggregate. Materials Research, v. 14, n. 2, p. 248-255, 2011.

SANTOS, D. R.Propriedades do Concreto Produzido Com Agregado Graúdo Reciclado de Resíduos da Etapa de Produção das Alvenarias. Goiânia, 2006. 131 f. Dissertação (Mestrado em Engenharia do Meio Ambiente) - Programa de Pós-Graduação em Engenharia do Meio Ambiente, Universidade Federal de Goiás, Goiânia, 2006.

SEARA-PAZ, S. et al. Bond Behavior Between Steel Reinforcement and Recycled Concrete. Materials and Structures, v. 47, p. 323-334, 2014.

SILVA, S. R.; ANDRADE, J. J. O. Investigation of Mechanical Properties and Carbonation of Concretes With Construction and Demolition Waste and Fly Ash. Construction and Building Materials, v. 153, p. 704-715, 2017.
TAM, V. W. Y.; GAO, X. F.; TAM, C. M. MicroStructural Analysis of Recycled Aggregate Concrete Produced From Two-Stage Mixing Approach. Cement and Concrete Research, v. 35, n. 6, p. 1195-1203, 2005.

TOPÇU, I. B.; GÜNÇAN, N. F. Using Waste Concrete as Aggregate. Cement and Concrete Research, v. 25, n. 7, p. 1385-1390, 1995.

VIEIRA, G. L. Estudo do Processo de Corrosão Sob a Ação de Íons Cloreto em Concretos Obtidos a Partir de Agregados Reciclados de Resíduos de Construção e Demolição. Porto Alegre, 2003. 150 f. Dissertação de (Mestrado em Engenharia Civil) - Programa de Pós-Graduação em Engenharia Civil, Universidade Federal do Rio Grande do Sul, Porto Alegre, 2003.

WERLE, A. P. Determinação de Propriedades de Concretos Com Agregados Reciclados de Concreto, Com Ênfase na Carbonatação. São Leopoldo, 2010. 162 f. Dissertação (Mestrado em Engenharia Civil) - Programa de Pós-Graduação em Engenharia Civil, Universidade do Vale do Rio dos Sinos, São Leopoldo, 2010.

YANG, J.; DU, Q.; BAO Y. Concrete With Recycled Concrete Aggregate and Crushed Clay Bricks. Construction and Building Materials, v. 25, p. 1935-1945, 2011.

ZEGA, C. J.; MAIO, A. A. Recycled Concrete Made With Different Natural Coarse Aggregates Exposed to High Temperature. Construction and Building Materials, v. 23, p. 2047-2052, 2009.

Ana Amélia Mota dos Santos

Programa de Pós-graduação de Engenharia Civil e Ambiental, Departamento de Tecnologia | Universidade Estadual de Feira de Santana | Av. Transnordestina, s/n, Campus Universitário, Novo Horizonte | Feira de Santana - BA - Brasil | CEP 44036-900 | Tel.: (75) 3161-8310 | E-mail: anamota.eng@gmail.com

Mônica Batista Leite

Programa de Pós-Graduação de Engenharia Civil e Ambiental, Departamento de Tecnologia | Universidade Estadual de Feira de Santana | Tel.: (75) 3224-8117 | E-mail: mleite.uefs@gmail.com

Revista Ambiente Construído

Associação Nacional de Tecnologia do Ambiente Construído

Av. Osvaldo Aranha, $99-3^{\circ}$ andar, Centro

Porto Alegre - RS - Brasil

CEP $90035-190$

Telefone: +55 (51) 3308-4084

Fax: +55 (51) 3308-4054

www.seer.ufrgs.br/ambienteconstruido

E-mail: ambienteconstruido@ufrgs.br 